\title{
Functional Organization of Corticocortical Projections from Area 17 to Area 18 in the Cat's Visual Cortex
}

\author{
David J. Price, José Manuel R. Ferrer, ${ }^{a}$ Colin Blakemore, and Nobuo Katob \\ University Laboratory of Physiology, Oxford OX1 3PT, United Kingdom
}

We used anatomical and physiological methods to study the functional organization of the association projection from area 17 to area 18 in the cat's visual cortex. Neurons in area 17 projecting to area 18 (revealed by retrograde transport of fluorescent tracer) tend to be clustered over regions of layer 4 receiving input from the ipsilateral eye (visualized by anterograde transneuronal tracing). Since the contralateral input overlaps these ipsilateral patches, the association cells lie preferentially in regions that are likely to be binocularly innervated. Indeed, almost all cells recorded electrophysiologically within the association clusters were strongly binocular, whereas between the clusters, many neurons were dominated by the contralateral eye. There is sufficient jitter in the retinotopic organization of area 17 for the discontinuous distribution of association cells to provide a continuous representation of the visual field.

Cells in each association cluster in the rostral part of area 17 project divergently to innervate a zone extending up to $3 \mathbf{~ m m}$ wide, anteroposteriorly, in the superficial layers of area 18. The receptive fields of cells at any point in area 18 are larger than for the corresponding point in area 17. Neurons recorded at two points in area 18, separated by a distance equal to the limit of anatomical divergence of the projection from area 17, have receptive fields that overlap by an amount similar to the region of visual field covered by the receptive fields of cells in a single association cluster in area 17 at a similar retinotopic position.

Thus, area 18 receives a full and strongly binocular representation of the visual field not only from the lateral geniculate nucleus but also from area 17 . The divergence of the area 17 to 18 projection compensates for the difference in receptive field size by ensuring that the receptive fields of each cluster of projecting neurons overlap fairly precisely those of the recipient neurons in area 18.

[Key words: association cells, ocular dominance, receptive field properties, retinotopic organization, convergent connections, divergent connections, visual cortex, cat]

Received March 5, 1993; revised Oct. 18, 1993; accepted Oct. 26, 1993.

D.J.P. was a Beit Memorial Research Fellow, J.M.R.F. was a Luis Manuel Foundation Fellow, and N.K. was supported by the Japanese Monbushoh and the Wellcome Trust. The project was funded by the Wellcome Trust, the Medical Research Council, the British Council, the Oxford McDonnell-Pew Centre for Cognitive Neuroscience, and DGICYT-PM91-0109. We are very grateful to Pat Cordery for help with histology.

Correspondence should be addressed to Dr. D. J. Price, Department of Physiology, University Medical School, Teviot Place, Edinburgh EH8 9AG, UK.

aPresent address: Department of Physiology, Faculty of Medicine, University of Granada, Granada 18012, Spain.

tPresent address: Department of Integrative Brain Science, Faculty of Medicine, Kyoto University, 606 Kyoto, Japan.

Copyright (c) 1994 Society for Neuroscience $0270-6474 / 94 / 142732-15 \$ 05.00 / 0$
We are interested in the organization and development of connections between areas of the visual cortex, and have previously described some of the striking changes that occur postnatally as the corticocortical pathway from area 17 to area 18 of the cat's visual cortex matures (Price and Blakemore, 1985a,b; Price and Zumbroich, 1989). Immediately after birth, association neurons in area 17 projecting to area 18 are distributed across both the superficial and the deep layers of area 17, as two continuous bands of roughly cqual ccll density (Pricc ct al., 1994).

Many previous studies have demonstrated that, in the adult cat, the projection originates mainly from dense clusters of neurons in the superficial layers, with few in the infragranular layers (Gilbert and Kelly, 1975; Symonds and Rosenquist, 1984; Price and Blakemore, 1985a,b; Gilbert and Wiesel, 1989), and that this clustered distribution of labeled cells in area 17 is not simply an artifact resulting from localized uptake of tracer from small injections in area 18 (Ferrer et al., 1988, 1992). This discontinuous projection pattern emerges from the immature distribution by about 3 weeks of age (Price and Blakemore, 1985a,b). In the mature cat, association cells in area 17 therefore sample at discrete intervals across the visual field representation: what information is being selected for transfer to area 18 ? In the visual cortex of Old-World monkeys, both within and between laminae, there is spatial segregation of association neurons with different functional properties, according to their targets in the extrastriate belt (see Zeki and Shipp, 1988, for a review). In the projection from primary to secondary visual cortex there appears to be a number of separate, parallel subsystems, most especially the color-selective cells found in the cytochrome oxidase-rich "blobs" in the superficial layers, which terminate in cytochrome oxidase-rich "thin stripes" of the second area (Livingstone and Hubel, 1983, 1984; DeYoe and Van Essen, 1985; Shipp and Zeki, 1985).

The cat does not have a distinct color pathway. However, there are "columnar" distributions of cells with similar functional properties, especially ocular dominance and preferred orientation, both forming regular periodic patterns whose repeat distances are quite similar to the spacing of the clusters of corticocortical cells. This raises the possibility that there is a specific functional relationship between the hypercolumn patterns in area 17 (Hubel and Wiesel, 1974; Albus, 1975b) and the intermittent distribution of cells projecting to area 18 . In this study we have combined neuroanatomical and electrophysiological methods to investigate any possible correlation between the distribution of association cells projecting to area 18 and the functional architecture of area 17.

Each small cluster of association cells in area 17 sends a divergent projection to a larger recipient zone in area 18 (Gilbcrt, 1985; Gilbert and Wiesel, 1985, 1989; Ferrer et al., 1988; Salin, 
1988). Pari passu, each small region in 18 receives a convergent projection from a larger territory in area 17 . In other experiments we have quantified this divergence and convergence (Ferrer et al., 1988, 1992), using techniques of analysis similar to those employed by Salin et al. (1989) to examine the afferent projections to area 17 . Clearly, there might be a functional correlation between the divergence and convergence of the input from area 17 to area 18 and the representation of the visual field in the two areas. In these experiments, we studied the relationship between the divergence from clusters of association cells in area 17, the retinotopic organization of the two areas, and the relative sizes of the receptive fields of cells at corresponding positions in areas 17 and 18 . This enabled us to derive estimates of the precision of the spatial sample provided by the association projection and the degree to which it coincides with the spatial representation of the target neurons.

\section{Materials and Methods}

Animals. Successful experiments were carried out on 10 normal adult cats. Two cats rcceived intraocular injections of tritiated proline, to reveal ocular dominance columns, and intracerebral microinjections of diamidino yellow (DY; Keizer et al., 1983) to label clusters of area 17 to 18 association cells. In a further four cats, injections of DY were made into area 18 , followed, after a short survival time, by electrophysiological recording from area 17 . In the final four cats, microelectrode penetrations were made into area 18 .

Intraocular injections. Two cats were deeply anesthetized with ketamine hydrochloride ( $22 \mathrm{mg} \cdot \mathrm{kg}^{-1}$, i.m.) and placed in a headholder. A small incision was made to extend the lateral canthus so as to reveal the sclera of the left eyeball and, in both animals, $2.5 \mathrm{mCi}$ of tritiated proline in $100 \mu 1$ of sterile saline was injected into the vitreous body. The tip of the syringe was viewed with an ophthalmoscope during the injection, which was made as close as possible to the retina. The wound was sutured and the animal recovered from the anesthetic: there were no signs of discomfort following this simple and rapid procedure. After 2-3 weeks, to allow transneuronal transport of the tracer to the cortex, injections of DY were made into area 18 , as described below, before terminal perfusion.

Injections of $D Y$ into area 18 . In the intraocularly injected cats, as well as in a further four animals, anesthesia was induced with ketamine hydrochloride $\left(22 \mathrm{mg} \cdot \mathrm{kg}^{-1}\right.$, i.m.) followed by alphaxalone-alphadolone (Saffan, Glaxovet) given intravenously as required to maintain deep surgical anesthesia (about $0.03 \mathrm{ml} \cdot \mathrm{min}^{-1}$ ). The animal was placed in a stereotaxic frame, and the electrocardiogram (ECG) was monitored continuously.

Through a small scalp incision, craniotomy, and durotomy, a single pressure injection of $500 \mathrm{nl}$ of a $2 \%$ solution of DY in sterile distilled water was made into area 18 in the left hemisphere of each cat, at a depth of $1 \mathrm{~mm}$. Injections were made into the rostral part of area 18 where it forms a narrow strip running along the crest of the lateral gyrus and is readily accessible. The entry points of the capillary were all roughly in the middle of area 18 , judging from the distributions of labeled cells in both area 17 and the lateral geniculate nucleus (LGN), and lay between the interaural plane (anteroposterior zero; AP0) and about $5 \mathrm{~mm}$ anterior, where area 18 represents the region of visual field $5-15^{\circ}$ below the horizontal meridian (Tusa et al., 1979). After injection, the wound in the scalp was sutured and the animal recovered from anesthesia. Antibiotics were given ( $0.1 \mathrm{ml}$ of Streptopen, i.m.) to prevent wound infections; none occurred. After $5 \mathrm{~d}$ survival, the two cats that had received intraocular tritiated proline were given a lethal overdose of sodium pentobarbitone $(30 \mathrm{mg}$, i.p.) and perfused with fixative (see below); the others were prepared for acute electrophysiological recording.

Electrophysiology. Eight cats, including those with DY injections in area 18 (four cases), were used for recording experiments. All animals were anesthetized with ketamine hydrochloride $\left(22 \mathrm{mg} \cdot \mathrm{kg}^{-1}, \mathrm{i} . \mathrm{m}\right.$.) followed by a continuous intravenous infusion of Saffan in normal saline. The rate of Saffan infusion, about $0.03 \mathrm{ml} \cdot \mathrm{min}^{-1}$, was adjusted throughout the experiment to maintain adequate anesthesia; at all times we ensured that the heart rate was regular and was not altered by potentially painful stimuli, and that the electroencephalogram showed a continuous slow-wave pattern that did not desynchronize. Animals were paralyzed with gallamine triethiodide (Flaxedil; $10 \mathrm{mg}(\mathrm{kg} \cdot \mathrm{hr})^{-1}$, i.v.) and artificially ventilated ( 30 strokes $\cdot \mathrm{min}^{-1}$ ) with air supplemented with carbon dioxide so as to maintain end-expiratory carbon dioxide at the value recorded before paralysis (about $5 \%$ ). Body temperature was monitored with a rectal probe and maintained at $37^{\circ} \mathrm{C}$ by a heating blanket.

Animals were placed in a stereotaxic frame (Eldridge, 1979) and tungsten-in-glass microelectrodes were lowered by means of a motorized microdrive into area 17 or area 18 through a small craniotomy and durotomy just rostral to AP0. Long penetrations were made through area 17 where it lies in the medial wall of the lateral gyrus at the same rostrocaudal level as the injection previously made in area 18 . We attempted to drive the electrode through the superficial layers of area 17 , where most of the cells of origin of the association pathway to area 18 lie. Recordings from area 18 were taken at rostrocaudal levels similar to those of penetrations in area 17 : in four animals, 19 short penetrations were made perpendicular to the cortex, and recordings were obtained from the superficial layers of area 18, the main terminal zone for association axons from area 17 (Price and Zumbroich, 1989). The entry positions of electrode penetrations were confirmed by direct observation of the fixed brain at the end of the experiment, and they were precisely reconstructed later from histological sections. In each cat we made a mediolateral row of penetrations, spaced at $1 \mathrm{~mm}$ intervals, and then another $3 \mathrm{~mm}$ rostral to the first.

Optical preparation and visual stimulation were identical to those described previously (Blakemore and Price, 1987). The receptive fields of isolated single units were studied at regular intervals along electrode tracks: hand-manipulated stimuli were back-projected on a screcn in front of the animal and the activity of units judged by listening to responses on an audio monitor. We have previously demonstrated that for the assessment of the more straightforward receptive field properties, qualitative methods provide essentially the same information as do quantitative techniques and are considerably quicker (Blakemore and Price, 1987). In this study, we concentrated particularly on properties that are known to vary periodically across the visual cortex, in particular, orientation preference and ocular dominance, but we also assessed directional preference, receptive field position, and size and unit type, that is, whether simple or complex and whether "end-stopped" or hypercomplex (Hubel and Wiesel, 1962, 1965).

To facilitate accurate reconstruction of electrode tracks, small electrolytic lesions were made at intervals along each penetration by passing current (3-5 $\mu \mathrm{A}$, tip negative, for 3-5 scc) through the microclectrode as it was withdrawn. At the end of the electrophysiological recording, the animal was killed by anesthetic overdose $(30 \mathrm{mg}$ sodium pentobarbitone, i.v.) and immediately perfused transcardially with normal saline followed rapidly by a solution of $10 \%$ paraformaldehyde in phosphate buffer and then a solution of $10 \%$ sucrose in phosphate buffer. The brain was removed and allowed to equilibrate fully in phosphate buffer containing $10 \%$ sucrose, before histological processing.

Histology. In brains that contained tritiated proline, $25-\mu \mathrm{m}$-thick coronal sections were cut on a freezing microtome. A 1 -in-3 series from these sections was used for autoradiography: they were coated with Nuclear Research Emulsion (Ilford, K5) using the loop technique of Jenkins $(1972)$ and left at $4^{\circ} \mathrm{C}$ in the dark to expose for 6 weeks before developing with D19 (Kodak). A second 1-in-3 series was reacted histochemically to reveal cytochrome oxidase activity, which aids the discrimination of laminae (Wong-Riley, 1979) and of the area 17/18 and $18 / 19$ borders in the cat (Price, 1985). The third 1-in-3 series was used for the identification of DY-labeled cells in the fluorescence microscope; these sections were counterstained with cresyl violet after analysis. Unfortunately, we were unable to identify DY-labeled cells reliably in sections prepared for autoradiography, nor was it possible to analyze the positions of DY-labeled cells and then coat sections with emulsion since this compromised the quality of the autoradiography. Therefore, analysis was based on a comparison of pairs of immediately adjacent sections, one set showing DY label, the other revealing patches of terminals labeled by injection of the left eye.

Coronal sections (50 $\mu \mathrm{m}$ thick) were cut from all the other brains, and all sections from the region of area 17 or 18 around the site of electrode penetrations were kept; DY-labeled cells were identified in area 17. Electrolytic lesions were located in these sections and the electrode tracks reconstructed with the aid of a camera lucida. Sections adjacent to the tracks were reacted for cytochrome oxidase activity. In all DY-injected cats, sections were also taken through the LGN for the identification of labeled cells.

Analysis. DY-labeled cells were visualized under high power in a fuorescence microscope and the positions of all labeled cells recorded 


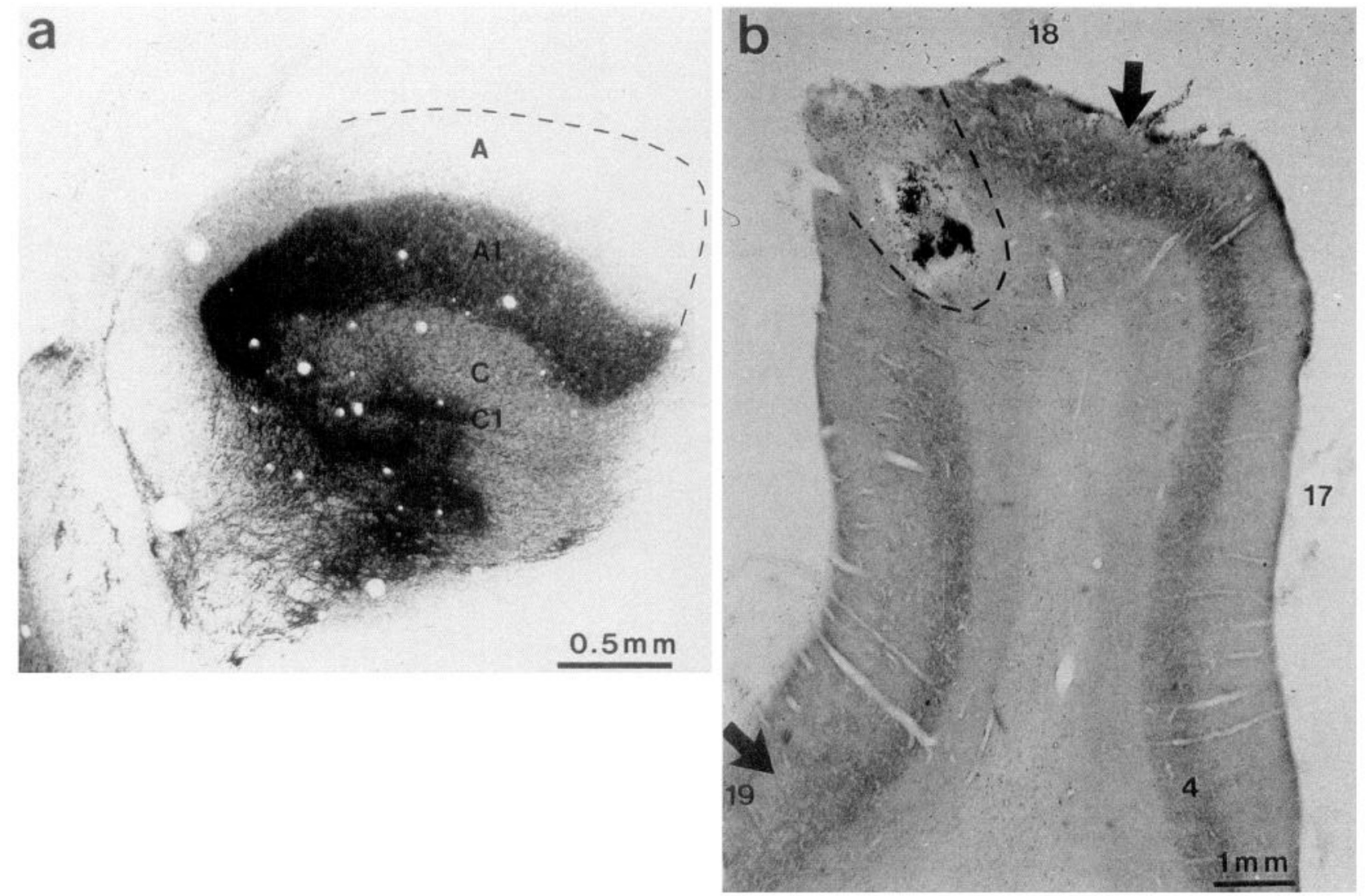

Figure 1. Bright-field photomicrographs of coronal sections through the left LGN and lateral gyrus of an adult cat. $a$, Autoradiogram showing anterogradely transported tritiated proline filling laminae $\mathrm{A} 1$ and $\mathrm{Cl}$ of the $\mathrm{LGN}$, ipsilateral to the injected eye. $b$, The visual cortex is stained histochemically for cytochrome oxidase. An injection of DY had been made in area 18 and the point of entry of the micropipette is revealed by local damage to the cortex and the collection of small dark dots, which are erythrocytes stained by cytochrome oxidase histochemistry. The broken line indicates the outline of the dense core of the injection site, visible in the fluorescence microscope before histochemical reaction. Layer 4 is revealed as a dark band running through areas 17 and 18, which declines sharply in intensity at the area 18/19 border (Price, 1985). The cytochrome oxidase staining, in conjunction with Nissl staining of adjacent sections, also helps reveal the area 17/18 border (Garey, 1971; Price, 1985). The positions of these borders are indicated by arrows. The fact that the injected tracer did not reach either of these borders in any animal was confirmed by studying the labeling of cells in the LGN (Price and Blakemore, 1985a,b). Note that the injection did not involve the white matter underlying area 18.

on drawings made through a camera lucida. Injections were verified as being in area 18 not only by direct inspection of the position of the injection site in cytochrome oxidase-and cresyl violet-stained sections, but also, as described previously, by examination of cells labeled in the LGN, to be sure that their sizes and distribution were appropriate for injection of area 18 (Price, 1985; Price and Blakemore, 1985a,b; Ferrer et al., 1988). Camera lucida drawings were made of the positions of all electrode penetrations and surrounding DY-labeled cells in area 17.

In the proline-injected animals, camera lucida drawings were made of the positions of all DY-labeled cells in the 1-in-3 series and these were used to create two-dimensional surface reconstructions of the clusters of association cells in area 17 (see Fig. 5a,d), using the method described in Ferrer et al. (1988). Adjacent sections in which we had revealed ocular dominance patches with the autoradiographic method were analyzed with the help of a computerized image analysis system (IBAS 2000 program) and were used to construct surface views of the distribution of labeled terminals (see Fig. $5 b, e$ ). The ocular dominance patches and association cell clusters were then directly compared by superimposition of the two surface maps (see Fig. $5 c, f$ ). Further details of the exact method of analysis of ocular dominance patches are given below.

\section{Results}

Correlation of ocular dominance patterns and clusters of association cells in area 17

Examination of area 17 in the two animals in which tritiated proline had been injected into the left eye and DY into area 18 of the left hemisphere allowed us to compare the distribution of association neurons with the pattern of afferent input from the ipsilateral eye. Labeled proline was transported from the eye to the LGN, where it evenly labeled the laminae innervated by the injected, ipsilateral left eye. Figure $1 a$ is a bright-field autoradiograph of a coronal section through the middle of the left LGN. Layers A1 and C1, receiving from the injected, ipsilateral eye, are heavily labeled throughout. An image analyzer was used to quantify the density of label in six equally spaced sections for each animal, and this confirmed an even distribution throughout most of each labeled lamina with the exception of its most lateral extreme, where the density was higher (probably due to extra label in axons). The completeness and uniformity of the labeling indicate that uptake occurred across the entire retina, which in turn suggests that transneuronal transport to the cortex was likely to be quite uniform, an important consideration in view of our use of quantitative analysis.

Sections through the lateral gyrus revealed that all the DY injection sites were entirely confined within area 18 , and that the dense core (the likely area of uptake of tracer; Bullier et al., 1984a; Ferrer et al., 1988) was about $1 \mathrm{~mm}$ in diameter and was limited to gray matter (Fig. $1 b$ ).

Figures 2 and 3 illustrate our procedure for comparing the 


\section{a}
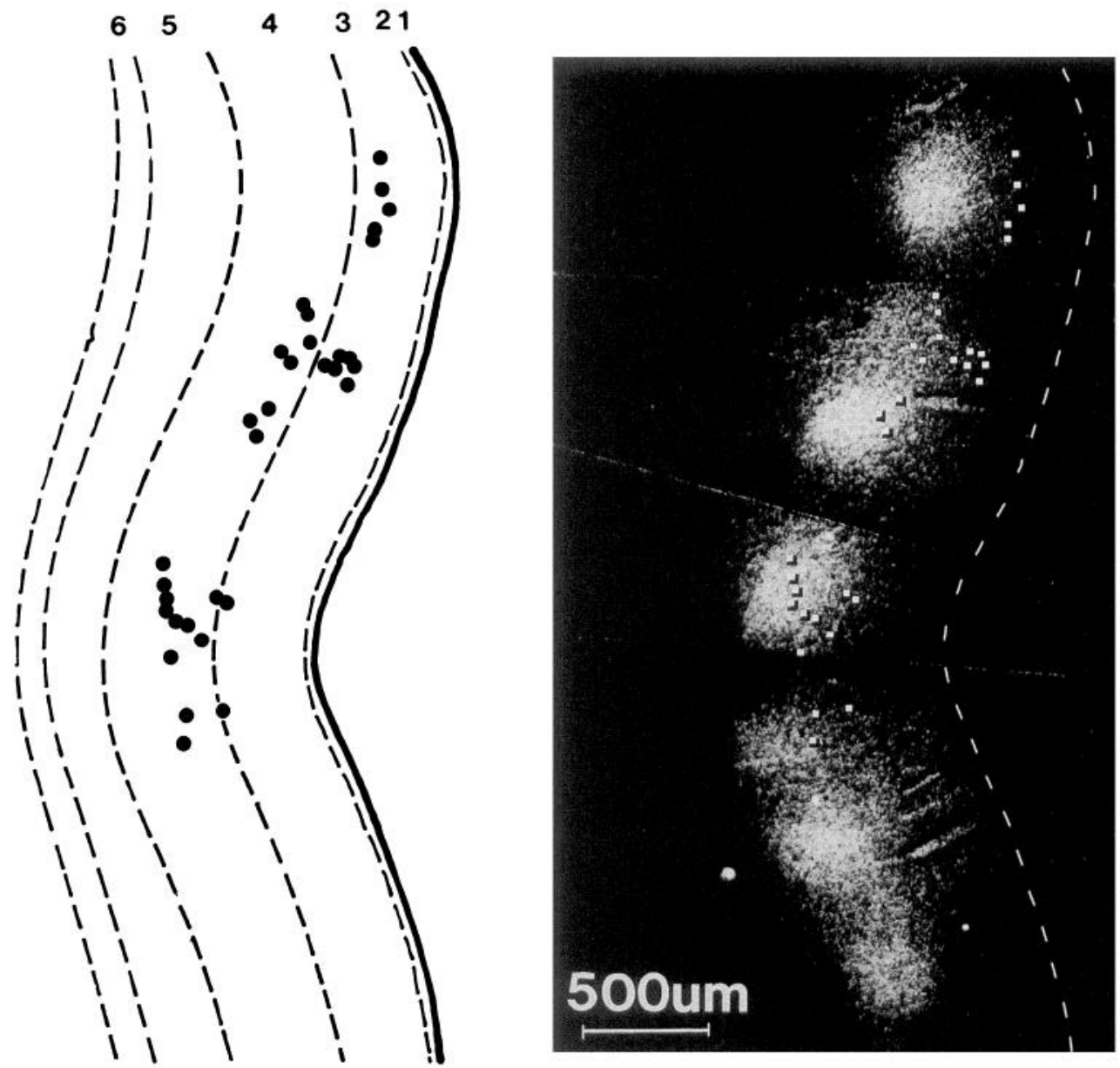

Figure 2. a, A camera lucida drawing of a coronal section through area 17 of the left visual cortex in the medial bank of the lateral gyrus of an adult cat showing the positions of all cells retrogradely labeled with DY after an injection into area 18 (circles). They lie in clusters, restricted to layers 2,3 , and the upper part of layer 4 in this example; occasional labeled cells were seen in infragranular layers in some sections, directly below the denser superficial clusters. $b$, The autoradiogram of a section immediately adjacent to that in $a$ is shown in this dark-field photomicrograph. The cat had received an injection of tritiated proline in the ipsilateral, left eye. Layer 4 is picked out by the dense labeling with silver grains, here seen as white (Shatz et al., 1977); the intensity of label in layer 4 fluctuates periodically. The cortical surface is indicated by the broken white line. The positions of the labeled cells marked in $a$ are superimposed on the photomicrograph (white dots). In this case, there appears to be a tendency for labeled cells to be concentrated over the patches of cortex that receive input from the ipsilateral eye. ocular dominance pattern with the distribution of association cells. Figure 2 shows an adjacent pair of sections through area 17 , in the medial bank of the lateral gyrus of the left hemisphere of a cat that received an injection of tritiated proline in the left eye and of DY in the left area 18. Figure $2 a$ is a camera lucida drawing of one section in which circles plot the positions of all association cells labeled with DY: they occur in clusters, and in this example, none lies in the infragranular layers. Figure $2 b$ is a dark-field autoradiograph of the immediately adjacent section, revealing geniculate terminals concentrated in layer 4 . Terminal labeling in this hemisphere, ipsilateral to the injected eye, lies mainly in dense patches, with gaps of much lower density between (Shatz et al., 1977). The positions of the labeled cells from Figure $2 a$ are superimposed on the photomicrograph in Figure $2 b$ (white dots). In this individual example there seems to be a tendency for the association cells to cluster over the regions of dense input from the ipsilateral eye.

Figure 3 shows camera lucida drawings of three different sections through the left area 17 from one of the animals, in which DY-labeled cells (circles) are seen distributed in clusters. Superimposed on each drawing is a representation of the patches of left-eye terminals seen in an adjacent section: the thin interrupted outlines show the boundaries of the dense regions of terminal labeling lying in layer 4 , as judged by eye (see below). While one example (Fig. $3 c$ ) has association clusters lying directly above ipsilateral terminal patches, the others (Fig. $3 a, b$ ) show some of them straddling the borders of patches. Occasionally, as for one cluster in Figure $3 a$, the cells largely overlie the space between patches. As Gilbert and Wiesel (1981) have suggested, it is hard to discern a consistent relationship between the two periodic distributions by observation of coronal sections.

It was clear that a more complete and rigorous analysis was required to reveal any interrelationship. Simple statistical comparison demanded the establishment of boundaries for each system of labeling. This was relatively easy for the association clusters because the density of labeled cells falls to zero in the gaps between clusters and our procedure of local density analysis (Ferrer et al., 1988) allowed us to determine the borders of each cluster quantitatively. The patches in layer 4 of area 17 labeled from the ipsilateral eye also appeared quite distinct (Fig. 2), and it was easy to assign boundaries by eye to each patch, with good 


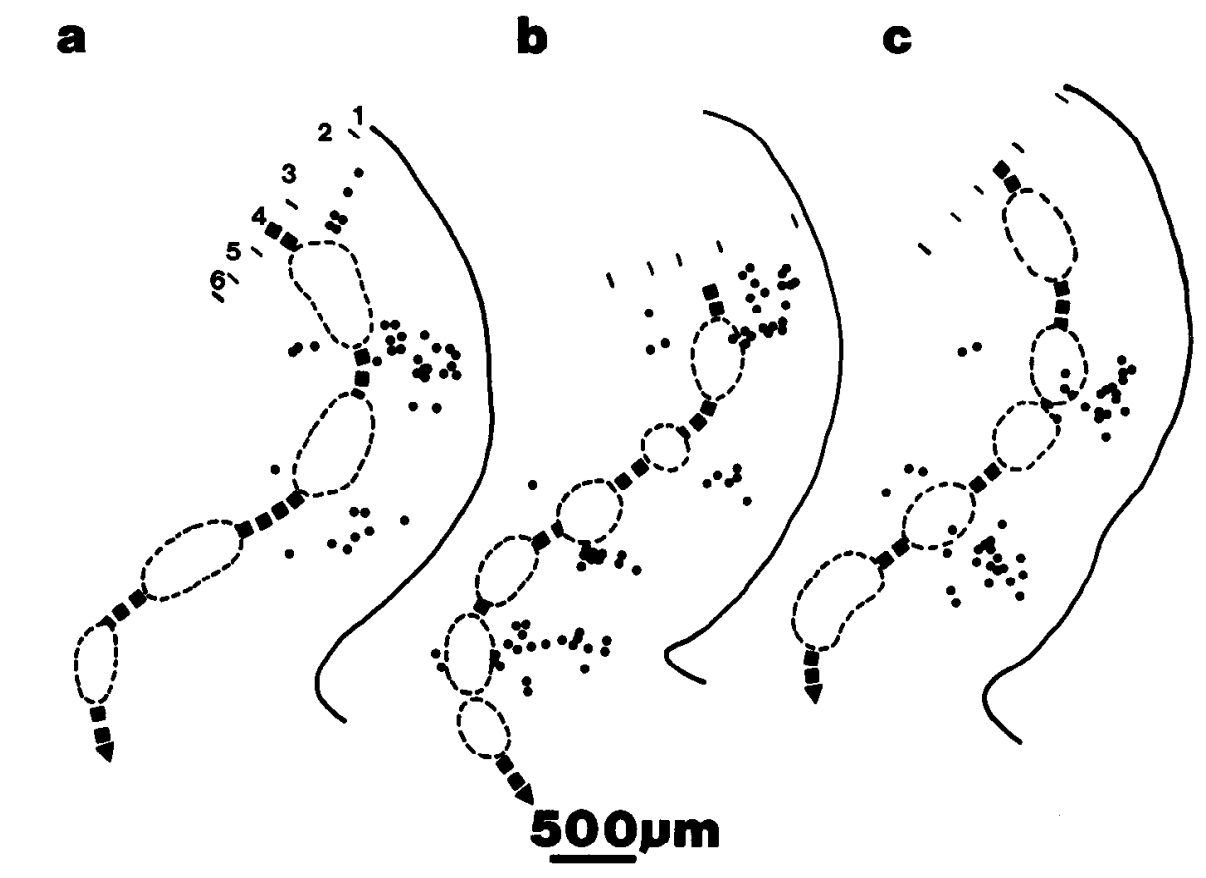

Figure 3. a-c, Camera lucida drawings of three coronal sections through area 17 ipsilateral to an injection of tritiated proline into the left eye; DY had been injected into arca 18 in the same hemisphere. As in Figure $2 b$, data from immediately adjacent sections are superimposed in each drawing. The positions of the retrogradely labeled cells, mainly in the superficial cortical laminae $(2,3$, and upper 4$)$, are indicated by circles. The areas outlined with broken lines, centered on layer 4 , show the patches of dense silver grains seen in autoradiographic sections; the boundaries of these regions of dense ipsilateral innervation were judged by eye. The along which silver grain densities were quantified; arrowheads show the direction of sampling (see Results and Fig. 4 for further details). thick broken lines indicate the tranches

agreement between independent observers. However, we were worried by the arbitrary nature of this procedure and decided to resort to quantification for the comparison with the distribution of association cells.

We used a computerized densitometer to measure the density of silver grains in layer 4 along a 50 - $\mu \mathrm{m}$-thick line drawn along the center of layer 4 parallel to the cortical surface in each section. The trajectory and width of this sampling tranche is indicated by the thick interrupted lines for the sample of sections in Figure 3.

Figure 4 plots the variation of optical density along the sampling tranche for a typical section; note that the higher the gray value in Figure 4, the lower the density of label. Background labeling (i.e., outside layer 4) varied slightly across some sections and, to a greater extent, between sections, especially those on different slides. Because of these baseline fluctuations, which were presumably largely due to slight differences in the coat of emulsion, it was impossible to employ an absolute threshold of grain density to define boundaries, and we set a criterion based on relative grain density. On either side of each peak, the point at which the gray level had fallen to midway between that of the peak and the adjacent trough was taken as the objective edge of the ocular dominance patch. The extent of the patches of ipsilateral input defined by this $50 \%$ criterion is indicated by vertical bars marked " 50 ;' in Figure 4. These estimates of the boundaries of regions of ipsilateral eye termination, which corresponded closely with subjective judgements of the edges by eye, could then be used for an objective comparison between ocular dominance stripes and clusters of association cells.

The quantitative autoradiographic data from the whole series of sections covering the region of area 17 containing retrogradely labeled cells were combined and interpolated to create twodimensional surface reconstructions of the ocular dominance patches (Fig. $5 b$ for one cat, Fig. $5 e$ for the other). The interleaved series of sections, covering precisely the same region of cortex, was used to generate matching two-dimensional reconstructions of the distribution of DY-labeled neurons (Fig. 5a,d). For each cat, both the ocular dominance and association cell distributions were reconstructed using the method described by Ferrer et al. (1988); the positions of labeled cells or the edges of ocular dominance patches were projected radially on to a single surface parallel plane. Then, as shown in Figure $5, c$ and $f$, the two reconstructions were superimposed for each cat. Inspection of these surface views suggested that there was, overall, a clear tendency for the clusters of association neurons to lie more frequently over the areas receiving ipsilateral input and to avoid the intervening regions (with input virtually exclusively from the contralateral eye).

To analyze the extent of this correlation, we counted the total numbers of DY-labeled cells that lay above patches of proline label (with boundaries defined by the $50 \%$ density criterion) and those that lay over the intervening spaces. Our series of sections, including both autoradiographic label and DY-labeled association clusters, covered tangential areas, projected on to the cortical surface, of $10.2 \mathrm{~mm}^{2}$ in one cat and $8.0 \mathrm{~mm}^{2}$ in the other (Fig. 5). The fraction of this total double-labeled area occupied by the regions of ipsilateral eye termination was $40.5 \%$ in the former case and $\mathbf{4 2 . 5 \%}$ in the latter (very similar to values reported by Shatz and Stryker, 1978). Thus, with the half-height criterion for defining autoradiographic boundaries, less than half the area of layer 4 was occupied by ipsilateral patches. However, a clear majority of labeled association cells lay within the boundaries of these ipsilateral eye regions. We counted $59.5 \%$ of labeled cells over ipsilateral patches (defined by the half-height criterion) in one animal and $58.5 \%$ in the other, and $\chi^{2}$ tests showed that both differences were highly significant $(p<0.0005$ for each).

The selection of a $50 \%$ criterion to define the patch boundaries was itself arbitrary, so for one of the two cats we examined the consequences of varying the threshold for defining the edges of ipsilateral eye patches. This enabled us to test whether there was any tendency for association cell clusters to concentrate above the very centers of ipsilateral patches or, perhaps, to lie more frequently over the boundaries between ipsilateral and purely contralateral regions. Since the fluctuation in grain density was roughly sinusoidal (Fig. 4), variation in the criterion 
for defining the edges of ipsilateral patches between $30 \%$ and $70 \%$ decrement in radioactive density generally had a relatively small effect on the positioning of the edges of the patches. With a $30 \%$ threshold, the tangential extent of layer 4 occupied by the patches fell to $35.5 \%$ of the total (shown by the bars marked "30" in Fig. 4). The proportion of association cells lying over these now smaller ipsilateral patches fell to 44.0\%; a $\chi^{2}$ test showed that the association was still highly significant $(p<$ 0.0005 ). Similarly, with a $70 \%$ criterion, increasing the area of the ipsilateral eye patches to $57 \%$ of the total surface parallel area (see Fig. 4), the fraction of association cells lying over the now-expanded ipsilateral patches rose to $71 \%$, and this still deviated significantly from what would be expected by chance $\left(p<0.0005, \chi^{2}\right.$ test).

We conclude that there is a significant bias in the positions of the association cells, such that they tend to lie more frequently over regions with ipsilateral input, but with no evidence that they cluster preferentially over the very centers or the edges of these ipsilateral patches.

\section{The physiological properties of striate neurons within association clusters projecting to area 18}

In four cats we attempted, with reasonable success, to record in the striate cortex from cells lying within clusters of association neurons projecting to area 18. To do this, we first injected DY at a single point in area 18 , to label the association clusters in a small region in area 17 , and later recorded with a microelectrode driven obliquely through the superficial layers of this part of area 17. The electrode track was then examined in sections prepared for fluorescence microscopy to reveal the association neurons. By determining the positions at which single units were recorded we were able, in each case, to locate the recording sites relative to the distribution of association cells.

Of course, there was no way of knowing whether the particular cells recorded, even within a DY-labeled clump, were themselves association neurons. It is likely that some were, since within the association clusters as many as $20 \%$ of all neurons were DY labeled. But in any case, throughout area 17 , closely neighboring cells usually have very similar receptive field properties. Therefore, we are confident that cells recorded within the association clusters either themselves projected to area 18 or had characteristics very similar to such neurons.

To record from area 17, we always entered the cortex directly medial to the injection in area 18 ; because of the distribution of retinotopic maps, and hence the topographic arrangement of the corticocortical connections, this is where we expected to encounter labeled cells (Ferrer et al., 1988). Nevertheless, this was a high-risk experiment in that we could not be sure in advance exactly where the labeled clusters in area 17 would be. Of a total of 12 penetrations through the supragranular layers of area 17, in which we recorded a total of 142 cells, six penetrations passed through regions containing distinct clumps of cells labeled from the injection in area 18. Of the total of 75 single units recorded along these parts of the tracks, just over half (40) lay in unlabeled regions between association clusters, but the remaining 35 cells were recorded within the boundaries of clusters of association cells. Of these units, 73 were clearly in layers II and III; the remaining two were on the border with layer IV (both were in association clusters).

Considering only the data from the 75 units that lay inside the entire area containing labeled association clusters, we compared the properties of neurons that lay inside the clumps with

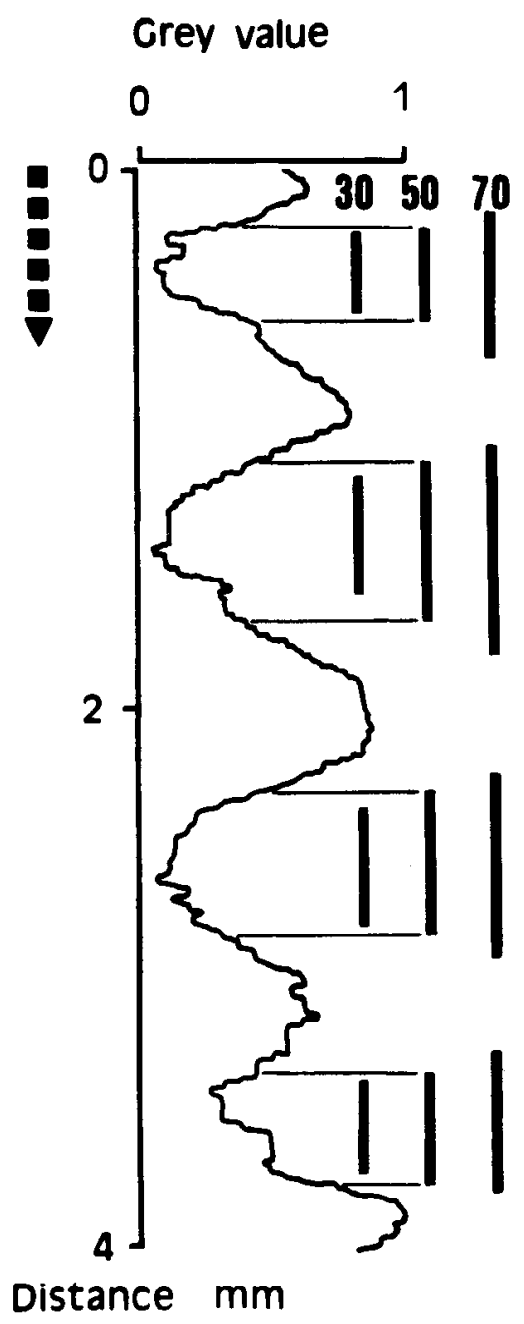

Figure 4. To quantify fluctuations of silver grain density along layer 4 and derive an objective measure of the edges of the ipsilateral patches, we used a computerized image analyzer to measure optical density along $50-\mu \mathrm{m}$-thick sampling tranches through layer 4 (thick broken lines in Fig. 3). Fluctuations in density along these lines were expressed as variation in gray value, where $1=$ low grain density and $0=$ high density. It is important to emphasize that the emulsion never seemed to be saturated. Even in the densest patches, individual silver grains could be resolved in the microscope and the gray level value approached but never reached the maximum value. We defined the boundaries of ipsilateral patches by criteria based on relative density (see Results). The thin horizontal lines indicate boundaries set at points at which density had fallen to halfway between peaks and neighboring troughs; the widtbs of these $50 \%$ criterion patches of ipsilateral input are indicated by the vertical bars marked 50. The slightly longer bars $(70)$ show the sizes of the patches defined by the $70 \%$ criterion for the fall in terminal density (a more liberal definition of ipsilateral patches), and the shorter bars (30) the sizes of patches defined by the $30 \%$ criterion (a more stringent definition).

those in between. Figures 6 and 7 show the distributions of ocular dominance and preferred orientation for these two groups.

The ocular dominance distribution for the whole sample of 75 units (Fig. 6, top right) shows a clear peak around group 4 (cells equally responsive through either eye), with a slight bias toward contralateral domination, just as previously reported for large samples of cells in cat area 17 (Hubel and Wiesel, 1962; Blakemore and Pettigrew, 1970; Blakemore and Van Sluyters, 1974). When the two populations (between and inside association clusters) were considered separately, this contralateral bias 


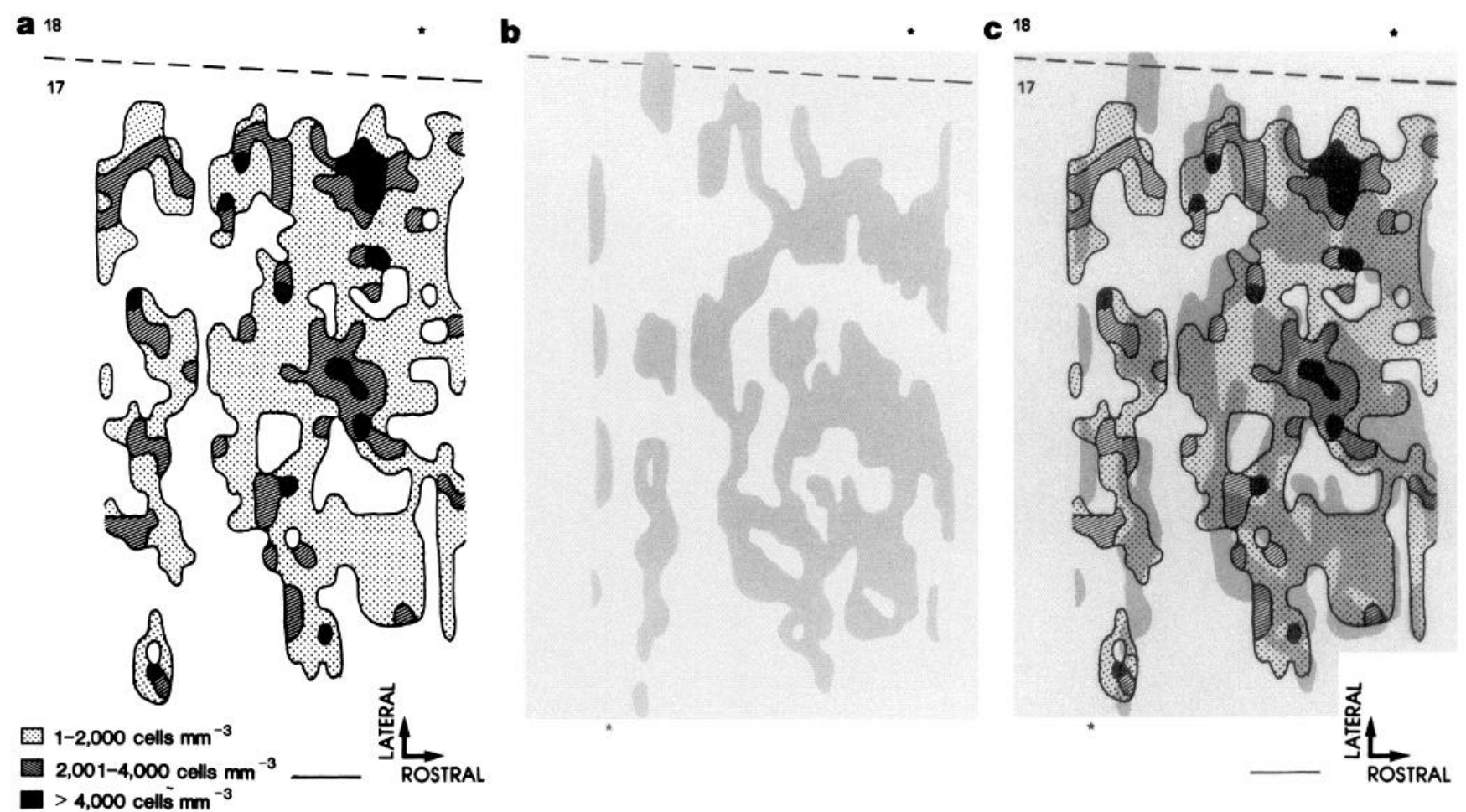

d

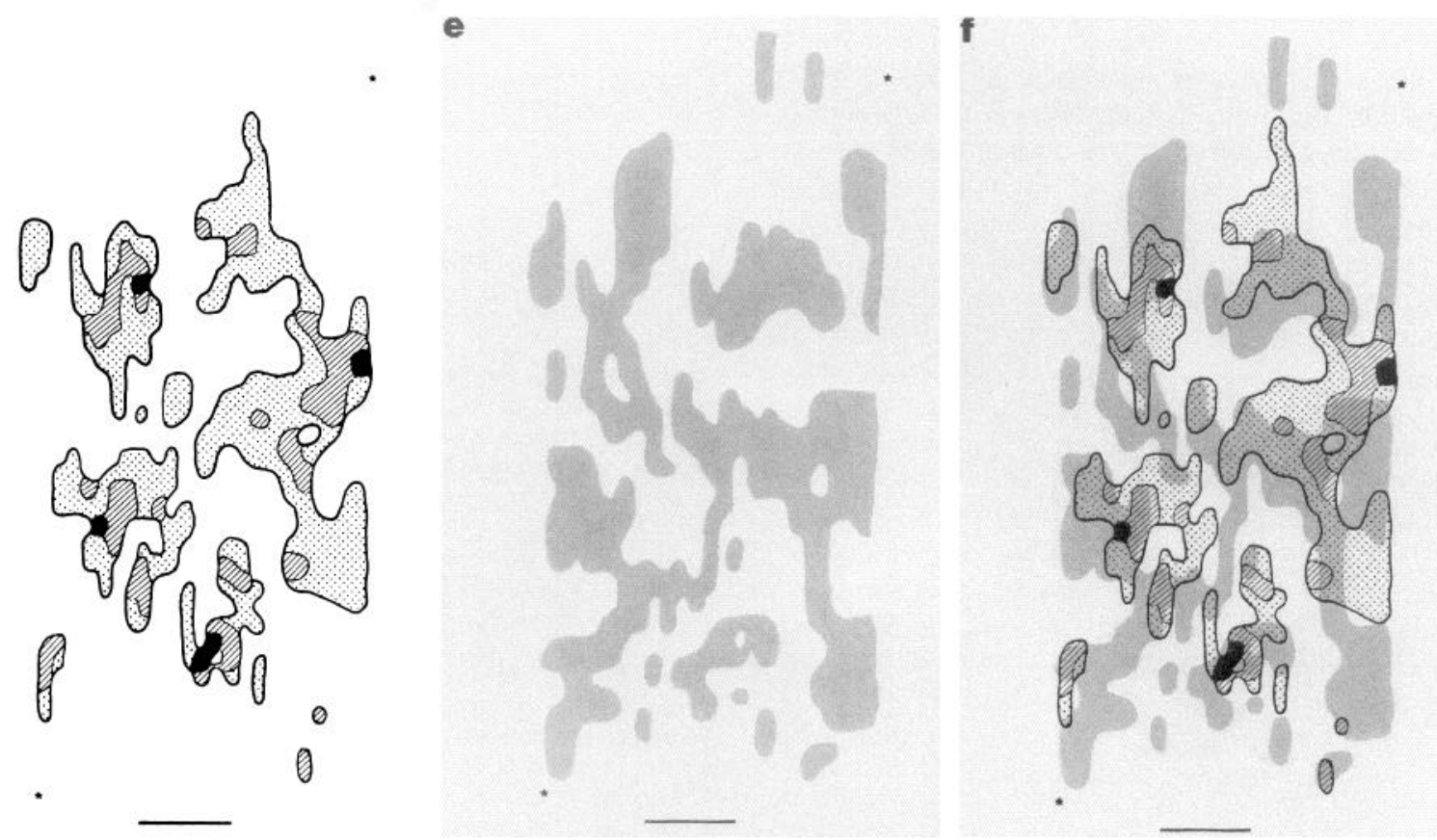

Figure 5. $a$ and $d$, Two-dimensional surface views of area 17, for two adult cats, reconstructed by the method of Ferrer et al. (1988) from a 1-in-3 series of $25-\mu \mathrm{m}$-thick coronal sections. These reconstructions consist of contour maps representing the density (see key in $a$ ) of the association cells labeled in superficial cortical layers (2, 3, and upper 4) after a single injection of DY into area 18 . In the first animal, the labeled area was closer to the area $17 / 18$ border (indicated by the broken line in $a$ ) but it was farther medial for the animal in $d$. $b$ and $e$, Similarly constructed twodimensional surface views of the ipsilateral ocular dominance patches in the same regions of area $17 ; b$ pairs with $a$, and $e$ with $d$. The diagrams show the regions of ipsilateral termination (shaded) with boundaries determined by the $50 \%$ criterion. In $b$, the area $17 / 18$ border is indicated by a broken line. $c$ and $f$, The clusters of association cells $(a$ and $d)$ are superimposed on the ipsilateral ocular dominance patches $(b$ and $e$ ), with edges set by the $50 \%$ criterion. In both animals there is a clear tendency for the dense clusters of association cells to avoid regions far from the areas of ipsilateral input, and most of the dense centers of clusters of association cells lie within the ipsilaterally innervated regions. Rostral/lateral orientations in $a$ refer to all drawings; stars are for alignment. Scale bars, $500 \mu \mathrm{m}$. 


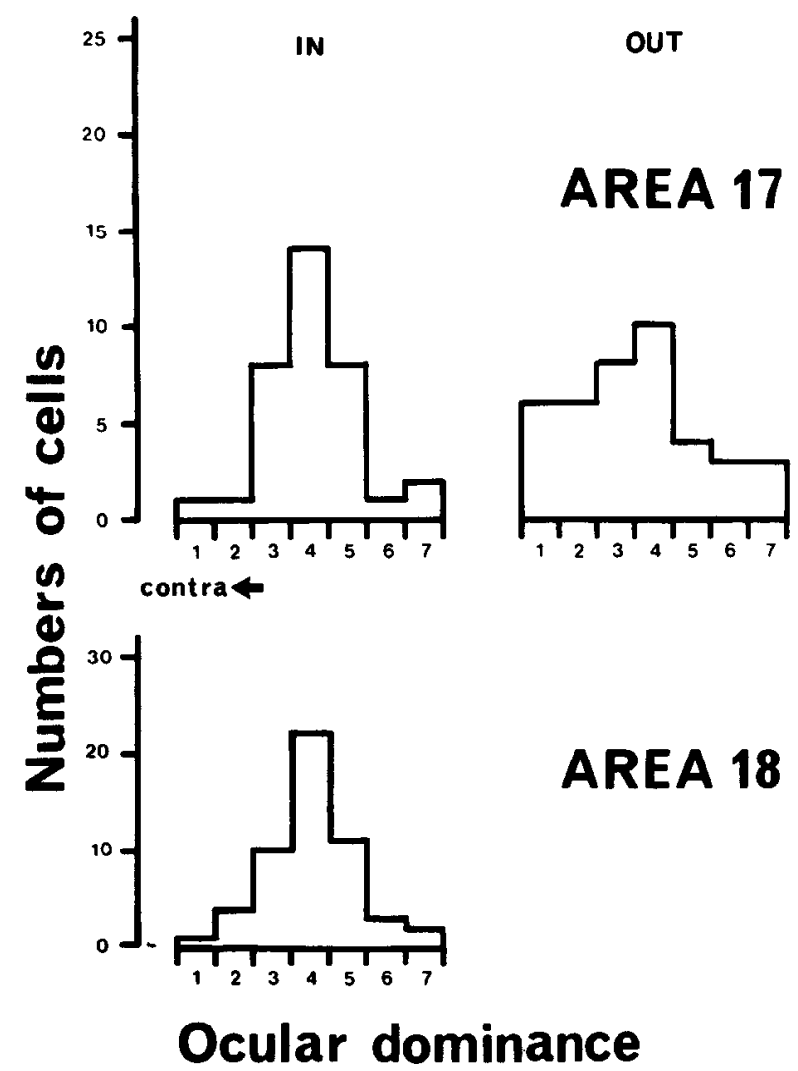

was much more striking for those units that lay between the clumps (Fig. 6, center top), whereas within the clusters, almost all units belonged to groups $3-5$; that is, they were strongly binocular (Fig. 6, top left).

As shown in Figure 7, our overall sample from area 17 contained cells with a full range of preferred orientations, and we could see no difference in this respect between cells within or between association clusters. We also assessed the preferred direction of movement for all cells recorded and found no dif-

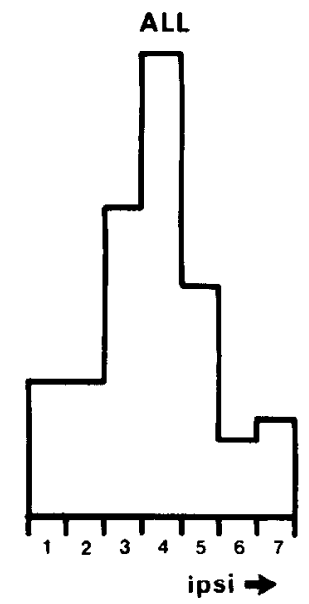

Figure 6. An analysis of ocular dominance for single units recorded in area 17 , both inside and between the clusters of cells retrogradely labeled from area $18(t o p)$, and in the supragranular layers of area 18 (bottom). Histograms are of the type introduced by Hubel and Wiesel (1962), classifying cells according to the relative strength of response through the two eyes. Cells in groups 1 and 7 are monocularly driven through the contralateral and ipsilateral eyes, respectively; those in group 4 are equally responsive through the two eyes. Separate histograms are shown for 35 cells recorded in area 17 inside the clusters $(I N), 40$ recorded between the labeled clusters $(O U T)$, and the combined sample $(A L L)$. Whereas inside the clusters few cells were monocularly dominated, in the regions between the clusters a larger proportion of cells was strongly monocularly dominated, especially by the contralateral eye. The histogram for 53 cells in the superficial layers of area 18 looked very similar to that for cells within clusters in area $17(I N)$.

ference in the distribution of their preferred directions within and between the association clusters.

We classified each cell according to its receptive field type, using previously published criteria (Blakemore and Van Sluyters, 1975; Blakemore and Price, 1987), based on Hubel and Wiesel's (1962) original descriptions. We found roughly similar numbers of simple and complex cells in our overall sample of units recorded in the supragranular layers of area 17, a fair proportion exhibiting obvious end-stopping ("hypercomplex"

$\mathbf{p}$

IN

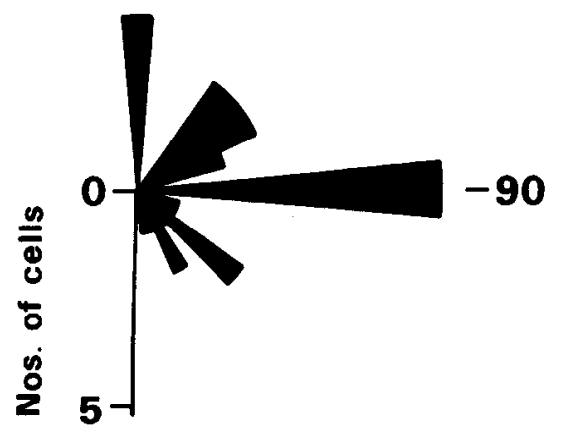

0

OUT 


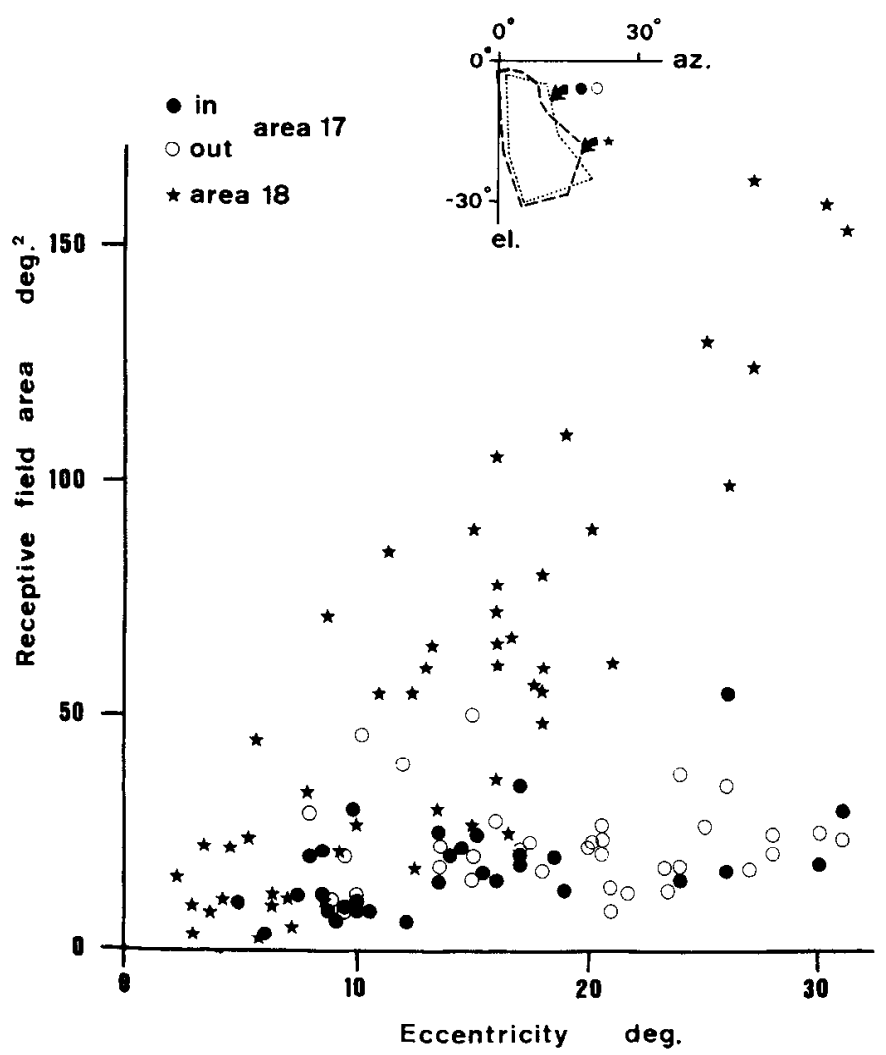

Figure 8. Graph showing the variation of receptive field size with distance from the area centralis for areas 17 and 18 . The sample of units recorded in area 17 is divided into those within association clusters (solid circles) and those between (open circles). There appears to be no consistent difference between the receptive field sizes of cells inside and outside the clusters in area 17. At a given eccentricity, cells in area 18 (stars) had larger receptive field sizes on average than those in area 17. The centers of the receptive fields of the units in the two cortical areas were scattered across very similar portions of visual space, as shown by the two outlined areas in the plot of the right lower quadrant of the visual field in the inset diagram (az., azimuth; $e l$. , elevation). A small number of cells in each sample could not be included because they were lost before their receptive fields were plotled in detail.

properties; see Hubel and Wiesel, 1965; Dreher, 1972; Rose, 1977). When we considered separately the samples of units recorded inside and between clusters of DY-labeled cells, we saw no differences in the proportions of these cell types.

Thus, cells within the boundaries of association clusters appeared, in most respects, to be indistinguishable in their physiological properties from those lying in the gaps between. The only difference that we found was the tendency for cells within clusters to be highly binocular, whereas the ocular dominance was skewed toward the contralateral eye for units recorded between the clumps.

\section{Ocular dominance of cells in superficial layers of area 18}

Many others have reported that cells in area 18 are strongly binocularly driven (Tretter et al., 1975; Hirsch and Leventhal, 1982; Sclar and Freeman, 1983; Blakemore and Price, 1987) and we confirmed this. The ocular dominance distribution looks very similar for cells within the association clusters in area 17 and cells in the superficial layers in area 18 (Fig. 6, bottom), the major recipient layers for the corticocortical projection from area 17 (Price and Zumbroich, 1989). Other aspects of the receptive fields of neurons in area 18 are presented below.
Representation of visual space in the association projection

We were particularly interested in obtaining estimates of the dimensions and scatter of the receptive fields of cells within and between association clusters in order to analyze the completeness of the spatial representation provided by the projection from area 17 to 18 . Therefore, we carefully plotted each receptive field as a response field (or "minimum response field"; Barlow et al., 1967), that is, the area of the visual field within which a moving bar or edge of the optimal orientation generated a response. Data for those 75 units that lay in the area containing labeled association clusters (see above) were analyzed further. Figure 8 plots the sizes of response fields (in degrees ${ }^{2}$ ), determined through the dominant eye, against their eccentricity from the area centralis (all units were in layers II and III). Data for cells recorded within and between association clusters are plotted with solid and open circles, respectively. The sample of cells recorded in area 17 shows the expected increase in average response field size with eccentricity (Hubel and Wiesel, 1965; Albus, 1975a) with no evidence that receptive field sizes differ consistently between units recorded inside and between association clusters.

It is well recognized that, within the overall retinotopic organization of area 17 , there is considerable variation in the dimensions of receptive fields and the scatter of their centers for cells recorded in radial penetrations (Albus, 1975a). Penetrations that passed roughly tangentially through more than one cluster (such as those analyzed in Figs. 9, 10), allowed us to see whether this local scatter is sufficient to ensure that a complete representation of the visual field is included within the system of association clusters, despite the gaps in their coverage of area 17. The result was clear. The receptive fields from adjacent clusters overlapped considerably, by an amount compatible with Albus (1975a) description (Figs. 9c, 10c), and there was even some overlap in the receptive fields from units in two nonadjacent clusters separated by a third (Fig. 9c). Thus, despite the truly discontinuous nature of the projection from area 17 to area 18 (Ferrer et al., 1988, 1992), an uninterrupted representation of the visual field is transmitted to area 18 .

\section{Relationship between the retinotopy of areas 17 and 18 and convergence and divergence of the association projection}

Ferrer et al. (1988) suggested that axons from area 17 project divergently to innervate a zone in area 18 about $1.6 \mathrm{~mm}$ (SD $\sim 0.5 \mathrm{~mm}$ ) larger in size, along the direction parallel to lines of iso-azimuth, than the diameter of the group of cells of origin in area 17. They also pointed out that the interpretation of patterns of convergence and divergence in functional terms depends crucially on knowledge of the retinotopic organization of the areas under study. Our present study is restricted to the rostral part of the visual cortex, where the representation of any particular line of iso-elevation in the visual field runs through striate and extrastriate areas in roughly a single coronal plane and lines of iso-azimuth run roughly rostrocaudally (Tusa et al., 1978, 1979). In this region individual association clusters are typically up to about $0.5 \mathrm{~mm}$ in rostrocaudal width, and a reasonable estimate of the total rostrocaudal spread of association axons in area 18 from a single cluster in 17 is about $3 \mathrm{~mm}$ (cluster width + mean divergence $+2 \mathrm{SD}$ ).

The situation is more complicated for the orthogonal axis, that is, along lines of iso-elevation, because area 18 is far narrower than area 17 and there is considerable variability from 

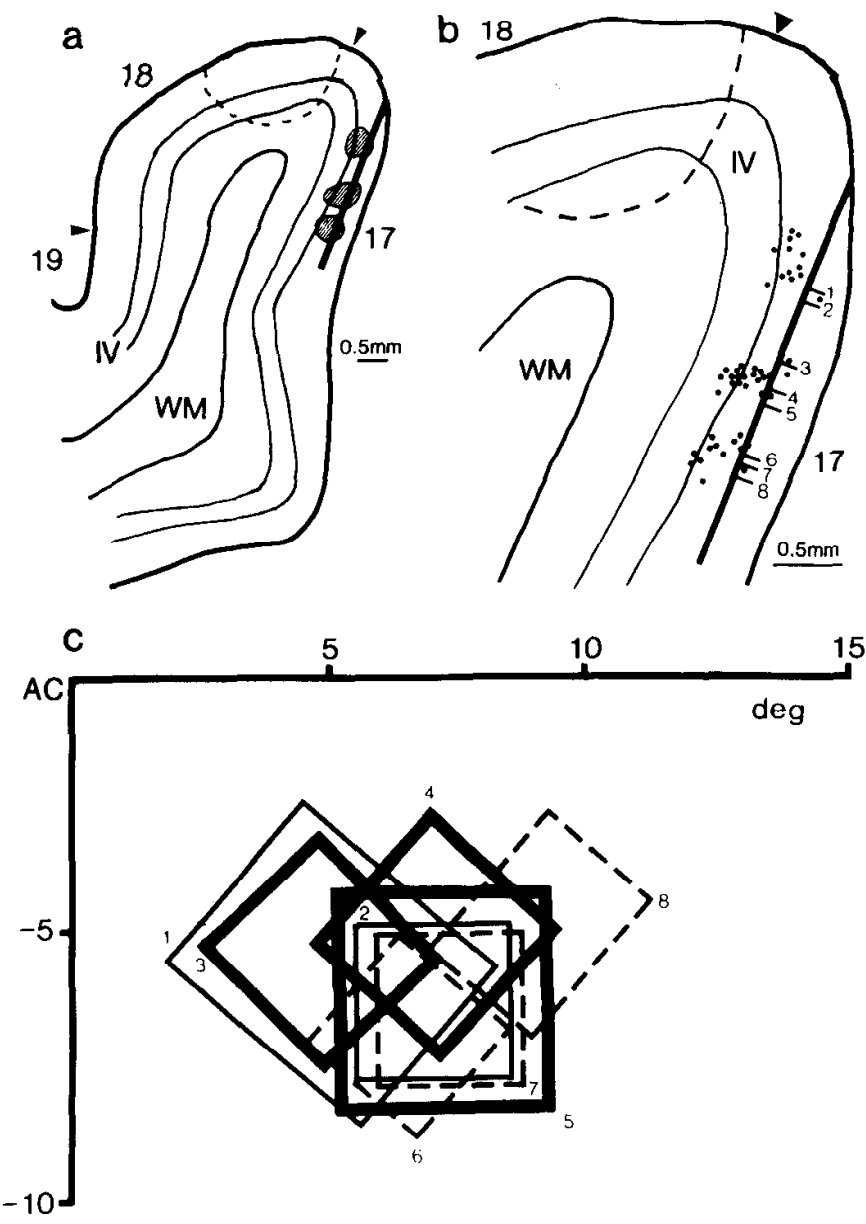

Figure 9. a, Camera lucida drawing of a coronal section through the left visual cortex showing an electrode penetration (thick line) through the superficial layers of area 17. The track ran through three clusters of cells (hatched) retrogradely labeled from an injection of DY into area 18 (injection site outlined with broken line). The area 17/18 and 18/19 borders are indicated by arrowheads. Layer 4 is marked; $W M$, white matter. $b$, An enlargement of the electrode track: individual labeled cells are shown as circles, and the positions of eight single units recorded within these clusters are numbered consecutively. Other units were recorded in the gaps between clusters, but for the sake of clarity, these are not shown. $c$, Representation of the right lower quadrant of the visual field with the area centralis at the origin, showing the receptive fields of the units in $b$. The receptive fields of units 1 and 2 are outlined with thin solid lines, those of units 3-5 with thick solid lines, and those of units 6-8 with broken lines. Note that although the recordings were madc within threc separate clusters, the receptive fields overlap sufficiently to cover the entire region of visual space represented in this part of area 17. Despite the discontinuous distribution of the cells of origin of the projection, a complete representation of the visual field is contained within the clusters projecting to area 18.

animal to animal in the exact retinotopy of area 18 in this direction (Tusa et al., 1979; Albus and Beckmann, 1980; Sanides and Albus, 1980). Because lines of iso-elevation deviate progressively from the coronal plane moving caudally in the cortex (Tusa et al., 1979), circular zones in area 18 are retinotopically equivalent to elongated zones in area 17 , oriented mediolaterally in rostral cortex and more rostrocaudally in posterior cortex (Fig. 11). Small, radially symmetrical injections in area 18 do indeed produce variously oriented elongated labeled territories in area 17 , exceeding the injection site in size by up to several
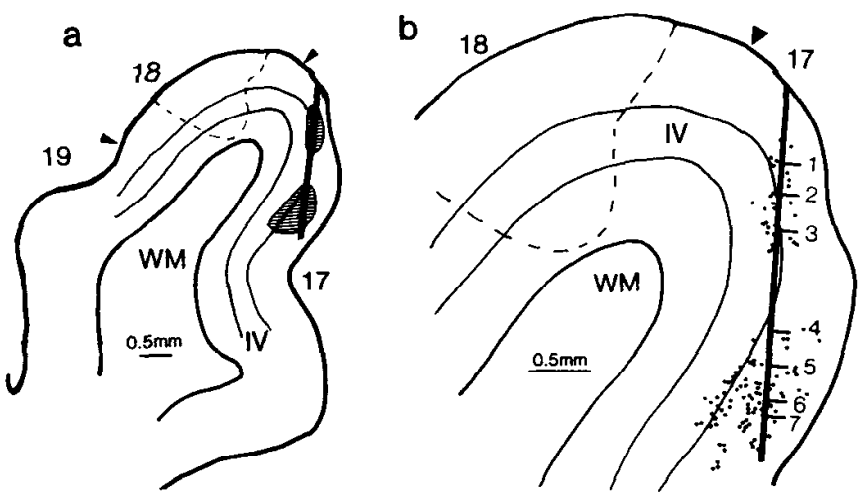

c

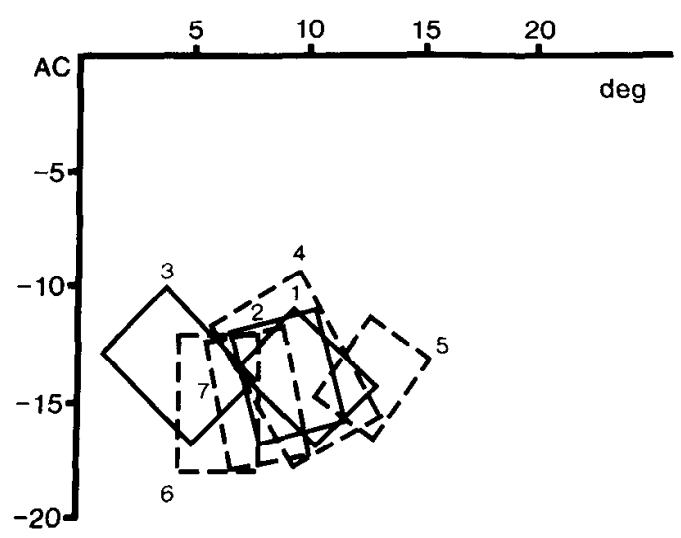

Figure 10. This shows data from another cat, using the same conventions as in Figure 9. In $c$, the receptive fields of units 1-3 are outlined with continuous lines, and those of 4-7 with broken lines.

millimeters in one axis (Ferrer et al., 1988, 1992; Salin, 1988; Gilbcrt and Wiesel, 1989; Henry ct al., 1991). The analysis of functional convergence must take account of retinotopic anisotropies. For these reasons, the analysis described here is restricted to the rostrocaudal direction and the rostral cortex.

We considered the relationship between the extent of the visual field covered by the receptive fields of the cells in each association cluster in area 17 and that of the neurons in the region of area 18 to which the cluster projects. We recorded from 53 single neurons in 19 short penetrations restricted to the superficial layers of area 18 , in four cats. As shown in the inset of Figure 8, the receptive fields of these units covered roughly the same total region of the visual field as those for the cells that we recorded in area 17. The sizes of their receptive fields, plotted as stars in Figure 8, tended to be larger than those of area 17 cells at the same eccentricity, confirming the observations of others (e.g., Hubel and Wiesel, 1965; Movshon et al., 1978; Tusa et al., 1978).

We wanted to know whether the divergence and convergence in the projection might relate in some way to the difference in receptive field sizes in the two areas, perhaps providing neurons at any point in area 18 with input from cells over a region of area 17 sufficiently wide that their smaller receptive fields extend over a region of the visual field equal to that covered by the larger receptive fields of the receiving cells in area 18, as suggested by Gilbert and Wiesel (1989).

We considered all penetrations into area 18 that were separated by $3 \mathrm{~mm}$ rostrocaudally, that is, at the extreme edges of the pattern of divergence of innervation from a typical associ- 
Figure 11. a, Schematic diagram of the rctinotopic organization of the whole of areas 17 and 18 on the unfolded lateral gyrus of the left hemisphere of the cat, simplified from Figure 2 of Tusa et al. (1979). Rostral is to the left, and the top of the diagram represents the part of area 17 that lies in the splenial sulcus. The thick line is the area $17 / 18$ border, which represents the vertical meridian $(V M)$. In each area, thin contours show lines of iso-azimuth, labeled in degrees from the vertical meridian into the contralateral hemifield. The representation of the horizontal meridian ( $H M)$ is shown as a thick interrupted line, and thin broken lines show lines of iso-elevation (negative values for lower field, positive for upper). The four circles along area 18 represent imaginary tracer uptake sites, $1 \mathrm{~mm}$ in diameter, and the stippled shapes in area 17 are the regions that correspond retinotopically to these "uptake sites." They are all elongated orthogonal to the area $17 / 18$ border, though to varying extents. Parallel to the border, each stippled region is the same size as the "uptake site" at its widest point, reflecting the similarity in elevational magnification, running along the two sides of the border. $b, \mathrm{~A}$ projection view of the medial surface of the left hemisphere of the cat, showing the actual distribution in space of the retinotopic map in area 17, simplified from rigure 5 of Tusa et al. (1978). The approximate position of APO is indicated with an arrow. The same conventions as in $a$ are used to display lines of iso-elevation and iso-azimuth, and the stippled shapes represent the same four regions in area 17 corresponding to the four "uptake sites" in area 18 , shown in $a$. Note that those in more rostral cortex (in the region explored by us and by Ferrer et al., 1988) are elongated mediolaterally, while the more caudal ones have long axes that are oblique or even anteroposterior.
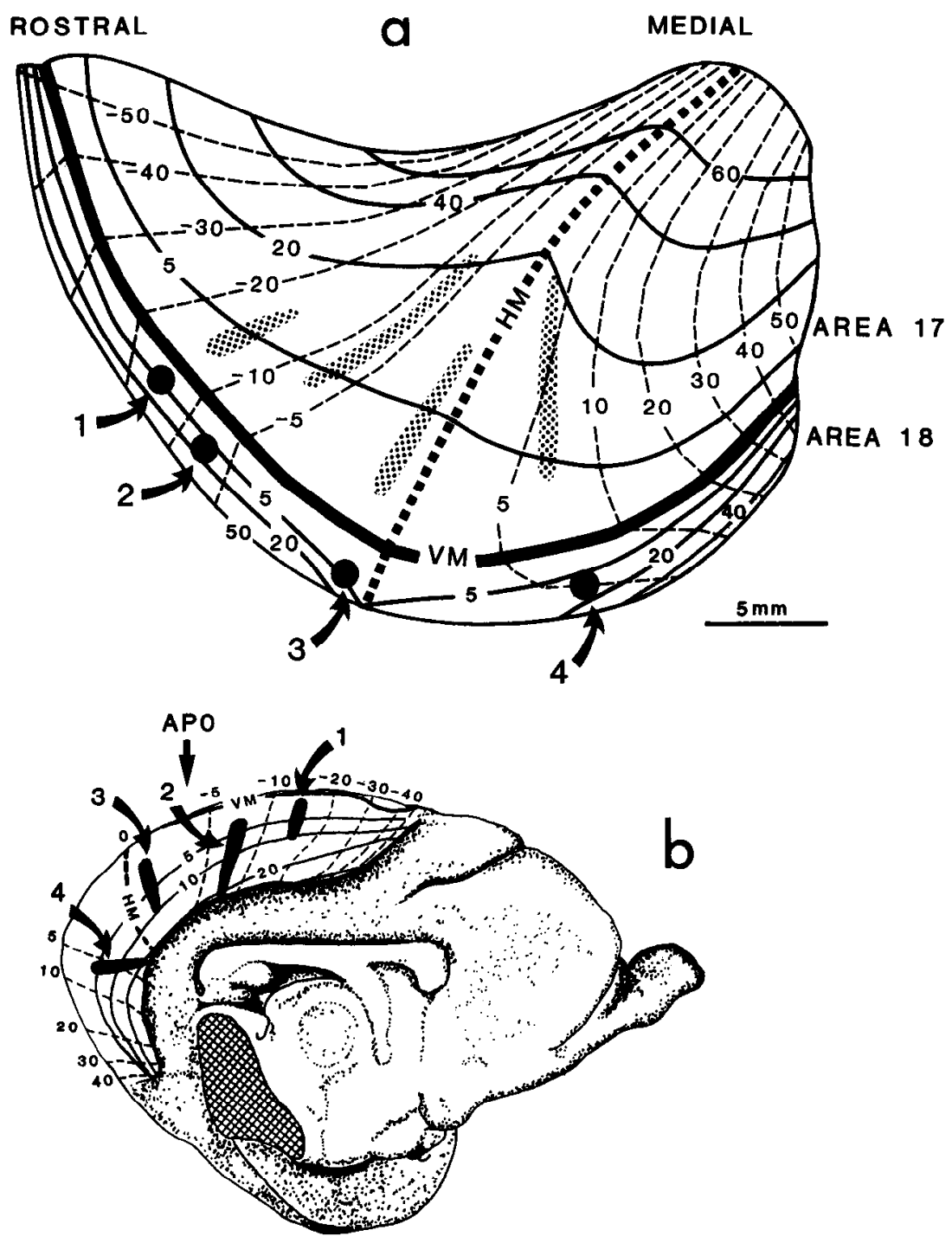

ation cluster in area 17 . If there were no overlap between the receptive fields of the cells recorded in these pairs of tracks, it would imply that the input from area 17 covers a wider area of the visual field than that represented in the receiving region of 18. However, there was substantial overlap between the receptive fields of units recorded in all these pairs of penetrations (Figs. 12, 13).

The receptive fields of units recorded within individual clusters of association cells in area 17 vary in size and are somewhat scattered (Figs. 9, 10, 12), as described previously by Albus (1975a). We were able to show that the array of receptive fields within single association clusters in a corresponding part of area 17 rather precisely fills the overlap between the receptive fields of units recorded $3 \mathrm{~mm}$ apart in area 18. This is illustrated in Figure 12. In this animal, two mediolateral rows of penetrations were made ( $1 \mathrm{~mm}$ apart within a row), the two rows being separated by $3 \mathrm{~mm}$ in the rostrocaudal direction. As expected from the retinotopic organization of area 18 in the adult cat (Tusa et al., 1979), the more lateral the penetrations, the farther the receptive fields lay from the vertical meridian; and the re- ceptive fields of cells recorded in the two caudal penetrations lay closer to the horizontal meridian than those of the units in the rostral penetrations. However, there was considerable overlap between the array of receptive fields of units recorded in the caudal row and that from the rostral row; the extent of this overlap is represented by stippling in Figure 12.

We then considered the receptive fields of all the units recorded inside a single association cluster in area 17 (six cells in the case in Fig. 12), whose receptive fields were centered on almost exactly the same region of visual space as the center of the stippled region of overlap in area 18. The receptive fields of these cells are shown in Figure $12 b$ : they are smaller on average than those of cells at the same eccentricity in area 18 , and the total region that they cover is quite similar to the extent of the region of overlap of the receptive fields of the cells recorded $3 \mathrm{~mm}$ apart in area 18 (to which such a cluster in area 17 could well project). Data from similar experiments in two other cats are presented in Figure 13 in the same form as those in Figure $12 b$. These data demonstrate that the extent of the convergence of the projection from area 17 is such that it could 
a
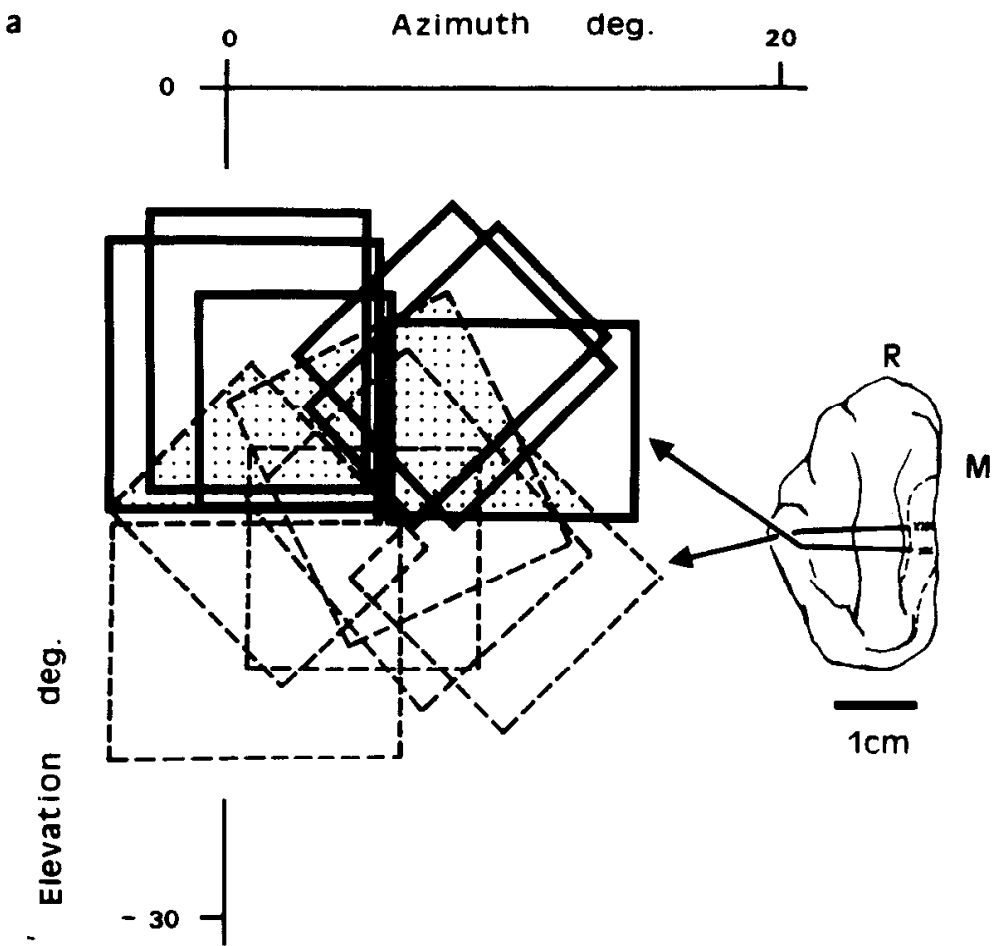

b

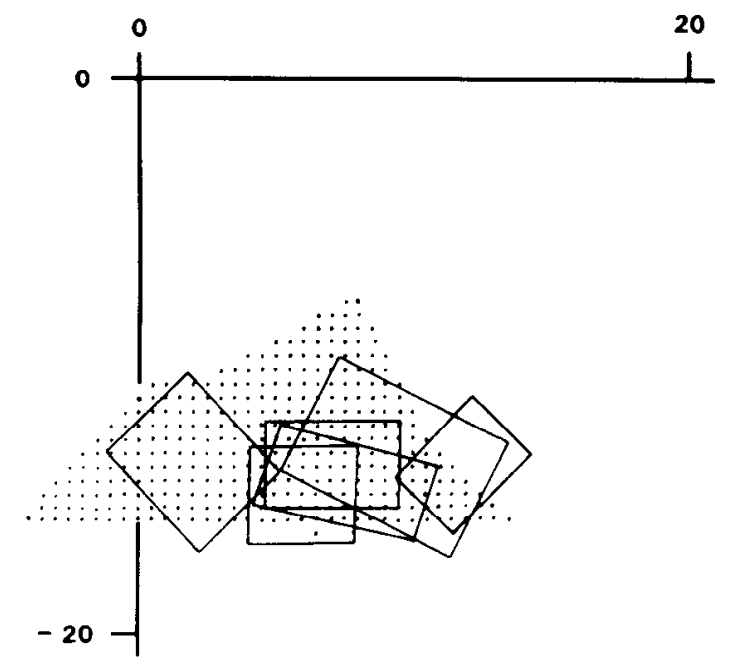

Figure 12. Results from an experiment designed to assess the compatibility between the divergence of the projection from area 17 to area 18 and the receptive field sizes and scatter in the two areas. Each diagram is a rcpresentation of the right lower quadrant of the visual field with the area centralis at the origin. $a$, Recordings were made in a number of penetrations in area 18 arranged in two mediolateral rows separated by $3 \mathrm{~mm}$ anteroposteriorly. The points of penetration are shown on a drawing of the left hemisphere (inset: area 18, which lies on the crest of the lateral gyrus, is outlined by broken lines; $R$, rostral; $M$, medial). Receptive fields of cells recorded in the superficial layers (2 and 3) of area 18 are shown on the diagram of the visual field. Those from the more caudal row of penetrations, outlined with continuous lines, lie closer to the horizontal meridian; those from the rostral row, outlined with broken lines, are farther from the horizontal meridian. There is considerable overlap of the two groups of receptive fields and this region of overlap is stippled. $b$, Receptive fields (outlined with continuous, thin lines) of six units recorded in a different cat within a single, small clump of labeled association cells in area 17. The receptive field array was centered on roughly the same region of visual space as the overlap area in $a$, and it can be seen that they cover a region quite similar in area and anteroposterior extent. Thus, cells in area 18 that are at the limits of the divergent projection from area 17 can share a region of the visual field similar in size to that represented in a single, small cluster in area 17 at the same retinotopic position. provide input from cells whose receptive fields just fill the area of visual field covered by the receptive fields of the cells in the receiving region in area 18 .

\section{Discussion}

The striate cortex, the major target of the retinogeniculate pathway in the cat, distributes information to several extrastriate visual areas, including areas 18 and 19 and the fields around the suprasylvian sulcus (Gilbert and Kelly, 1975; Bullier et al., 1984b; Symonds and Rosenquist, 1984; Ferrer et al., 1992). These diverse corticocortical projections all originate principally from neurons in the supragranular layers, and so they share a single retinotopic representation of the visual field and the same array of columnar systems. The cells of origin of each corticocortical pathway are not scattered uniformly across the cortex but lie in clusters, with an average center-to-center distance of about $0.75 \mathrm{~mm}$, with gaps in between (Ferrer et al., 1988, 1992). The clusters of association cells with different targets are not completely segregated but partially overlap each other (Bullier et al., 1984b; Ferrer et al., 1992). Thus, the pattern of each cluster system must determine the nature of the information transferred from the striate cortex to the target area of that system.

When we compared the physiological properties of neurons recorded within and between these clusters of association cells, the only obvious difference was a clear tendency for cells inside the clusters to have more balanced binocularity, while many cells in the gaps tended to be strongly dominated by the contralateral eye (Fig. 6). This result implies that there is a relationship between the ocular dominance columnar system and the clusters of association cells. A major part of our effort was directed at revealing this correlation with anatomical techniques.

\section{Correlation of association cell clusters with ocular dominance columns}

The use of transneuronally transported tritiated proline to demonstrate the ocular dominance columns allowed us to make a 
a

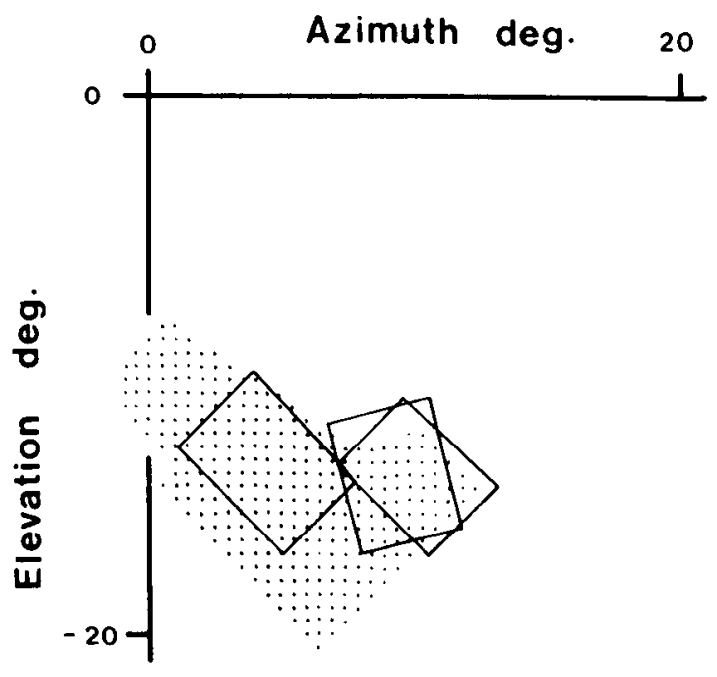

b

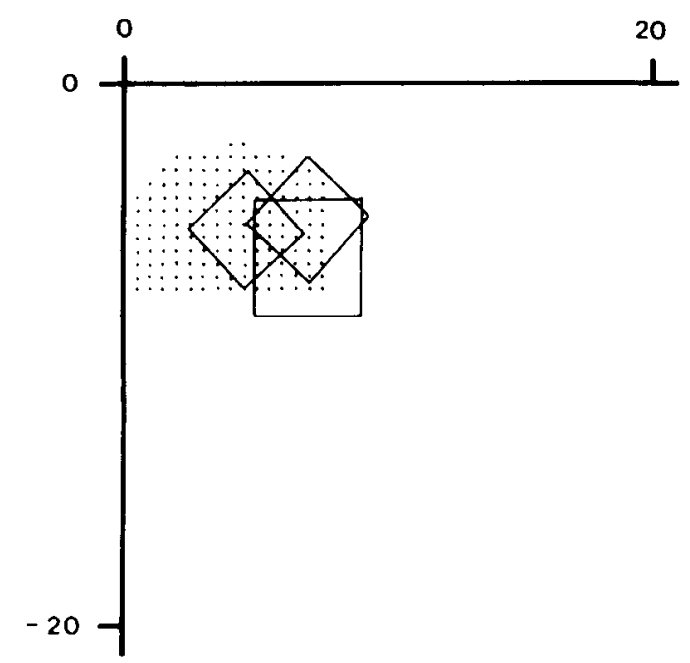

Figure 13. Data plotted as in Figure $12 b$ for two other cats. Stippling indicates the overlap of the receptive fields of cells in the superficial layers of area 18 in two sets of penetrations separated by $3 \mathrm{~mm}$ rostrocaudally. The receptive fields of units recorded in different cats within single clumps of labeled association cells at roughly corresponding retinotopic positions are superimposed. The eccentricities of the receptive fields in $b$ are smaller than in $a$, and there is a corresponding decrease in both the overlap of receptive fields for area 18 and the sizes of the receptive fields in area 17.

correlation with the clusters of association cells across a broad region of area 17 , a total of $18.2 \mathrm{~mm}^{2}$ tangential to the cortical surface in the two cats studied. The analysis required the precise comparison of two complex, three-dimensional systems largely lying in different layers. To deal with the difficulty of comparing the patches of tritiated proline in layer 4 and the association cells, mainly in layers 2 and 3 , we projected the two systems on to a single tangential plane equivalent to the cortical surface (Fig. 5). Although laborious, this method allowed us to estimate the correlation between the two periodic systems over the entire area of double labeling.

Even casual observation of the superimposed two-dimensional distributions in Figure 5 suggests that the association cell clusters avoid regions of the cortex far from any patch of ipsilateral termination. In the immediate neighborhood of each ipsilateral patch the relationship is less clear: association clusters are entirely absent above some parts of the proline patches and they spill over the edges in many regions, leading to the variability of appearance in individual sections (Fig. 3). However, there is clearly a broad correlation between the two systems: there was a significant correlation for all three criteria applied to define the edges of proline label. It seems that the association cells tend to be distributed fairly evenly above the ipsilateral patches.

In cats, input from the contralateral eye is more uniformly distributed along layer 4 than input from the ipsilateral eye (Shatz et al., 1977; Shatz and Stryker, 1978), and the discrete regions of dense input from the ipsilateral eye are superimposed on this more continuous background of contralateral terminals. Thus, layer 4 consists of alternating regions of contralateral input and binocular input (the latter corresponding to the ipsilateral patches). Presumably this organization accounts for the overall bias toward contralateral domination seen in large samples of neurons recorded in area 17 (Hubel and Wiesel, 1962; Blakemore and Pettigrew, 1970; Blakemore and Van Sluyters, 1974; see Fig. 6). By avoiding regions with only contralateral input, the clusters of association cells are selectively embedded in highly binocular regions of area 17 . This is confirmed by the physiological finding that cells recorded within the clusters are very rarely monocularly dominated (Fig. 6).

Cells in area 18 are, on average, more strongly binocularly dominated than those in area 17 (Hubel and Wiesel, 1965; Tretter et al., 1975; Hirsch and Leventhal, 1982; Blakemore and Price, 1987; Fig. 6). Indeed, the ocular dominance distribution for cells recorded in the superficial layers of area 18 (where association axons from area 17 mainly terminate) is strikingly similar to that of cells recorded within association clusters in the striate cortex (Fig. 6). This is one example of the functional matching of association neurons in area 17 and their target cells in area 18. However, the binocularity of cells in area 18 does not seem to depend on the corticocortical input from area 17: inactivation of area 17 by lesioning or cooling has little effect on the ocular dominance of cells recorded in area 18 (Dreher and Cottee, 1975; Sherk, 1978). The direct thalamic projection to area 18 must also be capable of providing strong binocular input.

Our data show that the degree of anatomical divergence and convergence of the projection from area 17 to area 18 is rather precisely related to the retinotopic organization, receptive field size, and scatter within the two visual areas. Injection of tracer into area 18 labels a group of clusters in area 17 that extends over a region of cortex that is wider than the injection site by an amount that is consistently related to the magnification factor (see Results). In terms of retinotopic coordinates, the territory in area 17 extends over a wider area of visual field than the uptake site in 18 , by a similar distance in visual field representation in all directions. If we take into account the variance of the estimate of divergence/convergence and the approximate diameter of individual association clusters in area 17, the likely total spread of axons from corticocortical cells in a single cluster in the rostral part of area 17 is to a region of area 18 extending 
about $3 \mathrm{~mm}$ in the rostrocaudal plane (see Results). Indeed, Ferrer et al. (1992) have shown that large injections of tracer into area 18 , which may be more effective in labeling sparsely distributed axons, do give consistently slightly larger values of convergence and divergence, confirming that up to $3.2 \mathrm{~mm}$ of the rostrocaudal extent of area 18 is innervated from each single small region of area 17 . We therefore took $3 \mathrm{~mm}$ as a reasonable estimate of the total rostrocaudal scatter of axons in area 18 from a single association cluster in area 17.

All this would seem to imply that the input from area 17 comes from a larger region of visual field than that represented in the receiving area in 18. However, the receptive fields of cells in area 18 are, on average, larger than those of cells in area 17 (see Fig. 8); our results suggest that convergence and divergence in the association pathway compensate for this difference by providing cells in area 18 with input from cells in area 17 whose receptive fields cover the same extent of visual space. The extent of overlap of receptive fields of cells recorded $3 \mathrm{~mm}$ apart in area 18 (near the edges of divergence of axons from a single association cluster) was indeed similar in size to the total region of visual space covered by samples of cells recorded within single association clusters in matched retinotopic positions in area 17 (Figs. 12, 13). The divergence of projections from area 17 to 18 is probably not a major factor in the production of the larger receptive fields of area 18 cells, since Dreher and Cottee (1975) have shown that inactivation of area 17 has little effect on the size of receptive fields in area 18.

Intrinsic corticocortical connections within the striate cortex are sufficiently widespread that they can provide input from regions of visual field outside the classical receptive fields of the receiving neurons (Ts'o et al., 1986). This is not necessarily the case for the association projection to area 18 , which may be more precisely positionally matched. However, the receptive fields of cells in area 18 are locally scattered and vary considerably in size (Figs. 8, 12). Therefore, many neurons in area 18 could receive some striate input from regions of visual field outside their conventional receptive fields-input that could contribute to subtle remote influences on their responses.

\section{Comparison between forward and reverse projections}

It is an attractive idea that the connections between visual areas in the cortex might exhibit what Henry et al. (1991) have called "global rcciprocity." This is the notion that there is quite precise spatial correspondence between forward and reverse projections, such that each group of neurons in one area feeds information back to the very cells in the preceding area that provide afferent input to that group. Indeed, Henry et al. (1991) have suggested that the interconnections of areas 17 and 18 in the cat might be matched in this way. On the other hand, Shipp and Zeki (1989) and Krubitzer and Kaas (1989) have argued that the reverse projection from area MT (or V5) to V2 in the macaque monkey is more divergent than the forward projection between them. One thing is certain: if average receptive field size increases from one area to the next (as it clearly tends to among the visual areas of the cortex) but magnification factor is similar (as it is along the rostrocaudal axis for areas 17 and 18 in the cat), no consistent arrangement of the reverse projection can possibly match the visual field representations. Even a reverse projection with no divergence and convergence would provide feedback from a wider region of visual field than that covered by the receptive fields of the cells on which it terminates in the earlier area. Recently, Salin et al. (1992) have used a combination of physiological and anatomical techniques, similar to ours, to study the feedback projection from area 18 in the cat (which is certainly convergent and divergent) and have indeed found that it provides input from a much wider region of visual field than that included in the receptive fields of the receiving cells in area 17 . Thus, there cannot be functional "global reciprocity" between areas 17 and 18 . The reverse projection must provide input from beyond the receptive fields of the cells that it innervates, while our results suggest that the forward projection is much more precisely visuotopically matched. This may be a rather general difference between forward and backward projections in the visual areas of the cortex and it surely has implications for differences in their functions.

\section{Developmental implications}

One might imagine that some sort of selective process occurring during development plays a part in establishing the remarkable precision of this association projection, linking cells with similar preferred orientations, ocular dominance, and overall receptive field positions. Indeed, Price and Blakemore (1985a) have already shown that the clustering of association neurons in area 17 gradually emerges postnatally from an initial uniform, dense band of cells projecting to area 18. Axon withdrawal without cell death seems largely if not entirely responsible for the loss of projections from neurons between the upper layer clusters (Price and Blakemore, 1985b). It is conceivable that some sort of coincidence detection, perhaps utilizing Hebbian synapses (Stent, 1973), might be involved in preserving and strengthening input to area 18 from cells in 17 whose receptive fields cover the same region of the visual field and respond to the same orientation.

On the other hand, a pattern of clusters emerges from the initial uniform band of association neurons even in the absence of patterned visual stimulation (Price and Blakemore, 1985a), although it remains to be seen whether they also appear after dark-rearing. It is possible that at least the gross arrangement of clusters is inherently determined, perhaps by local cues that also lead to the formation of coincident patches of ipsilateral eye termination. Certainly, the precise functional matching of properties between areas 17 and 18, within the clustered projection, may be achieved through experience-dependent modification. Further work is needed to determine the extent to which visual activity plays a part in constructing this beautifully organized pathway.

\section{References}

Albus K (1975a) A quantitative study of the projection area of the central and the paracentral visual field in area 17 of the cat. I. The precision of the topography. Exp Brain Res 24:159-179.

Albus K (1975b) A quantitative study of the projection area of the central and the paracentral visual field in area 17 of the cat. II. The spatial organization of the orientation domain. Exp Brain Res 24: 181-202.

Albus K, Beckmann R (1980) Second and third visual areas of the cat: interindividual variability in retinotopic arrangement and cortical location. J Physiol (Lond) 299:247-276.

Barlow HB, Blakemore C, Pettigrew JD (1967) The neural mechanism of binocular depth discrimination. J Physiol (Lond) 193:327-342.

Blakemore C, Pettigrew JD (1970) Eye dominance in the visual cortex. Nature 225:426-429

Blakemore C, Price DJ (1987) The organization and post-natal development of area 18 of the cat's visual cortex. J Physiol (Lond) 384: 263-292.

Blakemore C, Van Sluyters RC (1974) Reversal of the physiological 
effects of monocular deprivation in kittens: further evidence for a sensitive period. J Physiol (Lond) 237:195-216.

Blakemore C, Van Sluyters RC (1975) Innate and environmental factors in the development of the kitten's visual cortex. J Physiol (Lond) 248:663-716.

Bullier J, Kennedy H, Salinger W (1984a) Bifurcation of subcortical afferents to visual area 17,18 and 19 in the cat cortex. J Comp Neurol 228:309-328.

Bullier J, Kennedy H, Salinger W (1984b) Branching and laminar origin of projections between visual cortical areas in the cat. J Comp Neurol 228:329-341.

DeYoe EA, Van Essen DC (1985) Segregation of efferent connections and receptive field properties in visual area $\mathrm{V} 2$ of the macaque. Nature 317:58-61.

Dreher B (1972) Hypercomplex cells in the cat's striate cortex. Invest Ophthalmol 11:355-356.

Dreher B, Cottee LJ (1975) Visual receptive-field properties of cells in area 18 of cat's cerebral cortex before and after acute lesions in area 17. J Neurophysiol 38:735-750.

Eldridge JL (1979) Bi-axial stereotaxic head holder. J Physiol (Lond) 295:2P-3P.

Ferrer JMR, Price DJ, Blakemore C (1988) The organization of corticocortical projections from area 17 to area 18 of the cat's visual cortex. Proc R Soc Lond [Biol] 233:77-98.

Ferrer JMR, Kato N, Price DJ (1992) The organization of association projections from area 17 to areas 18 and 19 and to suprasylvian areas in the cat's visual cortex. J Comp Neurol 316:261-278.

Garey LJ (1971) A light and electron microscopic study of the visual cortex of the cat and monkey. Proc R Soc Lond [Biol] 179:21-40.

Gilbert CD (1985) Horizontal integration in the ncocortex. Trends Neurosci 8:160-165.

Gilbert CD, Kelly JP (1975) The projections of cells in different layers of the cat's visual cortex. J Comp Neurol 163:81-106.

Gilbert CD, Wiesel TN (1981) Projection bands in visual cortex. Soc Neurosci Abstr 7:356.

Gilbert CD, Wiesel TN (1985) Intrinsic connectivity and receptive field properties in visual cortex. Vision Res 25:365-374.

Gilbert CD, Wiesel TN (1989) Columnar specificity of intrinsic horizontal connections in cat visual cortex. J Neurosci 9:2432-2442.

Henry GH, Salin PA, Bullier J (1991) Projections from areas 18 and 19 to cat striate cortex: divergence and laminar specificity. Eur $\mathbf{J}$ Neurosci 3:186-200.

Hirsch HVB, Leventhal AG (1982) Effects of monocular deprivation on the binocularity of cells in area 18 of cat visual cortex. Dev Brain Res 8:140-144.

Hubel DH, Wiesel TN (1962) Receptive fields, binocular interaction and functional architecture in the cat's visual cortex. J Physiol (Lond) 160:106-154.

Hubel DH, Wiesel TN (1965) Receptive fields and functional architecture in two nonstriate visual areas (18 and 19) of the cat. J Neurophysiol 28:229-289.

Hubel DH, Wiesel TN (1974) Sequence regularity and geometry of orientation columns in the monkey striate cortex. J Comp Neurol 158:267-294.

Jenkins EC (1972) Wire loop application of liquid emulsion to slides for autoradiography in light microscopy. Stain Technol 47:23-26.

Keizer K, Kuypers HGJM, Huisman AM, Dann O (1983) Diamidino yellow dihydrochloride (DY $2 \mathrm{HCl}$ ); a new fluorescent retrograde neuronal tracer, which migrates only very slowly out of the cell. Exp Brain Res 51:179-191.

Krubitzer LA, Kaas JH (1989) Corticocortical integration of parallel pathways in the visual system of primates. Brain Res 478:161-165.

Livingstone MS, Hubel DH (1983) Specificity of corticocortical connections in monkey visual cortex. Nature 304:531-534.

Livingstone MS, Hubel DH (1984) Anatomy and physiology of a color system in the primate visual cortex. J Neurosci 4:309-356.

Movshon JA, Thompson ID, Tolhurst DJ (1978) Spatial and temporal contrast sensitivity of neurones in areas 17 and 18 of the cat's visual cortex. J Physiol (Lond) 283:101-120.

Price DJ (1985) Patterns of cytochrome oxidase activity in area 17, 18 and 19 of the visual cortex of cats and kittens. Exp Brain Res 58: $125-133$

Price DJ, Blakemore C (1985a) The postnatal development of the association projection from visual cortical area 17 to area 18 in the cat. J Neurosci 5:2443-2452.

Price DJ, Blakemore C (1985b) Regressive events in the postnatal development of association projections in the visual cortex. Nature 316:721-724.

Price DJ, Zumbroich TJ (1989) Postnatal development of corticocortical efferents from area 17 in the cat's visual cortex. J Neurosci 9:600-613.

Price DJ, Ferrer JMR, Blakemore C, Kato N (1994) Postnatal development and plasticity of corticocortical projections from area 17 to area 18 in the cat's visual cortex. J Neurosci 14:2747-2762.

Rose D (1977) Responses of single units in cat visual cortex to moving bars of light as a function of bar length. J Physiol (Lond) 271:1-23.

Salin P (1988) Etude de l'organisation topographique des afférents à l'aire striée du chat adulte par une méthode de double-marquage. Thèse de Doctorat en Médicine, Université Claude-Bernard Lyon I.

Salin PA, Bullier J, Kennedy H (1989) Convergence and divergence in the afferent projections to cat area 17. J Comp Neurol 283:486512.

Salin PA, Girard P, Kennedy H, Bullier J (1992) Visuotopic organization of corticocortical connections in the visual system of the cat. J Comp Neurol 320:415-434.

Sanides D, Albus K (1980) The distribution of interhemispheric projections in area 18 of the cat: coincidence with discontinuities of the representation of the visual field in the second visual area (V2). Exp Brain Res 38:237-240.

Sclar G, Freeman R (1983) Regional variations in the effects of monocular deprivation on area 18 of the cat. Exp Brain Res 51:388-396.

Shatz CJ, Stryker MP (1978) Ocular dominance in layer IV of the cat's visual cortex and the effects of monocular deprivation. J Physiol (Lond) 281:267-283.

Shatz CJ, Lindstrom S, Wiesel TN (1977) The distribution of afferents representing the right and left eyes in the cat's visual cortex. Brain Res 131:103-116.

Sherk H (1978) Area 18 cell responses in cat during reversible inactivation of area 17. J Neurophysiol 41:204-215.

Shipp S, Zeki S (1985) Segregation of pathways leading from area V2 to areas V4 and V5 of macaque monkey visual cortex. Nature 315: 322-325.

Shipp S, Zeki S (1989) The organization of connections between areas V 5 and V 2 in macaque monkey visual cortex. Eur J Neurosci 1:333354.

Stent GS (1973) A physiological mechanism for Hebb's postulate of learning. Proc Natl Acad Sci USA 70:997-1001.

Symonds LL, Rosenquist AC (1984) Corticocortical connections among visual areas in the cat. J Comp Neurol 229:1-38.

Tretter F, Cynader M, Singer W (1975) Cat parastriate cortex: a primary or secondary visual area. J Neurophysiol 38:1099-1113.

Ts'o D, Gilbert CD, Wiesel T (1986) Relationships between horizontal interactions and functional architecture in cat striate cortex as revealed by cross-correlation analysis. J Neurosci 6:1160-1170.

Tusa RJ, Palmer LA, Rosenquist AC (1978) The retinotopic organization of area 17 (striate cortex) in the cat. J Comp Neurol 177 . 213-236.

Tusa RJ, Rosenquist AC, Palmer LA (1979) Retinotopic organization of areas 18 and 19 in the cat. J Comp Neurol 185:657-678.

Wong-Riley $M$ (1979) Changes in the visual system of monocularly sutured or enucleated cats demonstrable with cytochrome oxidase histochemistry. Brain Res 171:11-28.

Zeki S, Shipp S (1988) The functional logic of corticocortical connections. Nature 335:311-317. 